\title{
HIV supply chains in low- and middle-income countries: Overview and research opportunities
}

\begin{abstract}
Purpose. Despite HIV being reported as one of the major global health issues, availability and accessibility of HIV services and supplies remain limited, especially in low- and middle-income countries. The effective and efficient operation of HIV supply chains is critical to tackle this problem. This paper gives an introduction to HIV supply chains in low- and middle-income countries and identifies research opportunities for the operations research/operations management (OR/OM) community.

Design/methodology/approach. First, we review a combination of scientific and grey literature, including both qualitative and quantitative papers, to give an overview of HIV supply chain operations in low- and middle-income countries and the challenges that are faced by organizing such supply chains. We then classify and discuss relevant OR/OM literature based on seven classification criteria: decision level, methodology, type of HIV service modelled, challenges, performance measures, real-life applicability, and countries covered. Because research on HIV supply chains in low- and middle-income countries is limited in the OR/OM field, this part also includes papers focusing on HIV supply chain modelling in high-income countries.
\end{abstract}

Findings. We conclude this study by identifying several tendencies and gaps, and by proposing future research directions for OR/OM research.

Originality. To the best of our knowledge, this paper is the first literature review addressing this specific topic from an OR/OM perspective.

Keywords: healthcare; HIV supply chain; low- and middle-income countries; literature review

\section{Introduction}

The human immunodeficiency virus (HIV) remains one of the most challenging health problems in the world (WHO, 2019a). HIV damages the body's immune system by attacking the CD4 cells, which are responsible for fighting off infections. If treatment with antiretroviral (ARV) drugs is not timely and effective, an HIV infection can progress into the acquired immune deficiency syndrome (AIDS), a deadly disease (Keller, 2016; WHO, 2017b). The death toll of HIV/AIDS lies beyond 32 million people so far (WHO, 2019a). At the end of 2018, approximately 37.9 million people were infected with HIV. Moreover, HIV is most prevalent in low- and middle-income countries (LMICs). Particularly the African continent is hit by HIV, with over two-thirds of all infected people being situated in this part of the world.

The third goal of the 17 Sustainable Development Goals set by the United Nations in 2015 aims at realizing global access to HIV services. Furthermore, this goal includes the end of HIV/AIDS being a global health issue by 2030 (i.e., zero new HIV infections, zero deaths linked to HIV, and zero 
discrimination related to HIV) (UN, 2019; WHO, 2017a). Reaching these objectives is very challenging for healthcare delivery systems in LMICs, which are already strained (Jamieson \& Kellerman, 2016). A necessity for achieving these goals is the availability and accessibility of HIV services. This, in turn, depends on the effective and efficient operation of HIV supply chains (Ripin et al., 2014; Xiong et al., 2008).

In this paper, we address three main research questions. First, how are HIV supply chains operated in LMICs and what challenges are faced by organizing such supply chains? Second, how did current operations research/operations management $(\mathrm{OR} / \mathrm{OM})$ literature contribute to the organization of HIV supply chain operations? Third, in what ways can future OR/OM research contribute to improve HIV supply chains in LMICs?

The contribution of this paper to the current literature is three-fold. First, we give an overview of the services, operations and main challenges of HIV supply chains in LMICs. To obtain a complete overview that is relevant for researchers and practitioners alike, we include a combination of (i) scientific and grey literature, and (ii) quantitative and qualitative papers in our review. To the best of our knowledge, this paper is the first literature review addressing this specific topic from an OR/OM perspective. Second, we classify and discuss the relevant OR/OM papers according to various classification criteria. Third, throughout these classifications, we identify gaps that provide opportunities for future OR/OM research.

The remainder of this paper is organized as follows. Section 2 provides background information on general health supply chains in LMICs. The literature search method applied in this paper is explained in Section 3. The first part of the literature review is presented in Section 4 and gives an overview of the HIV services (Section 4.1), the operation of HIV supply chains in LMICs (Section 4.2), and the challenges faced by organizing such supply chains (Section 4.3). Section 5 presents the second part of the literature review. Based on the services, operation and challenges of HIV supply chains described in Section 4, Section 5 classifies and discusses the relevant OR/OM literature, thereby providing suggestions for future research. Finally, Section 6 presents the main conclusions.

\section{Background on health supply chains in low- and middle-income countries}

The management of health supply chains is complicated as patients all over the world have specific needs for medical supplies according to their health status. Regarding this supply chain, there is a lot of room for improvement, especially in LMICs (Beier, 1995; Haszlinna Mustaffa \& Potter, 2009; McKone-Sweet, Hamilton, \& Willis, 2005).

An overview of the organization of health supply chains in LMICs is shown in Figure 1. Whereas in high-income countries private sector companies control health supply chains, in LMICs private, 
public, and non-governmental companies coincide as transmission channels for health products. As can be derived from Figure 1, some collaboration exists between these channels.

Figure 1: Overview of health supply chains in LMICs (reprinted from Yadav, Tata, and Babaley (2011)).

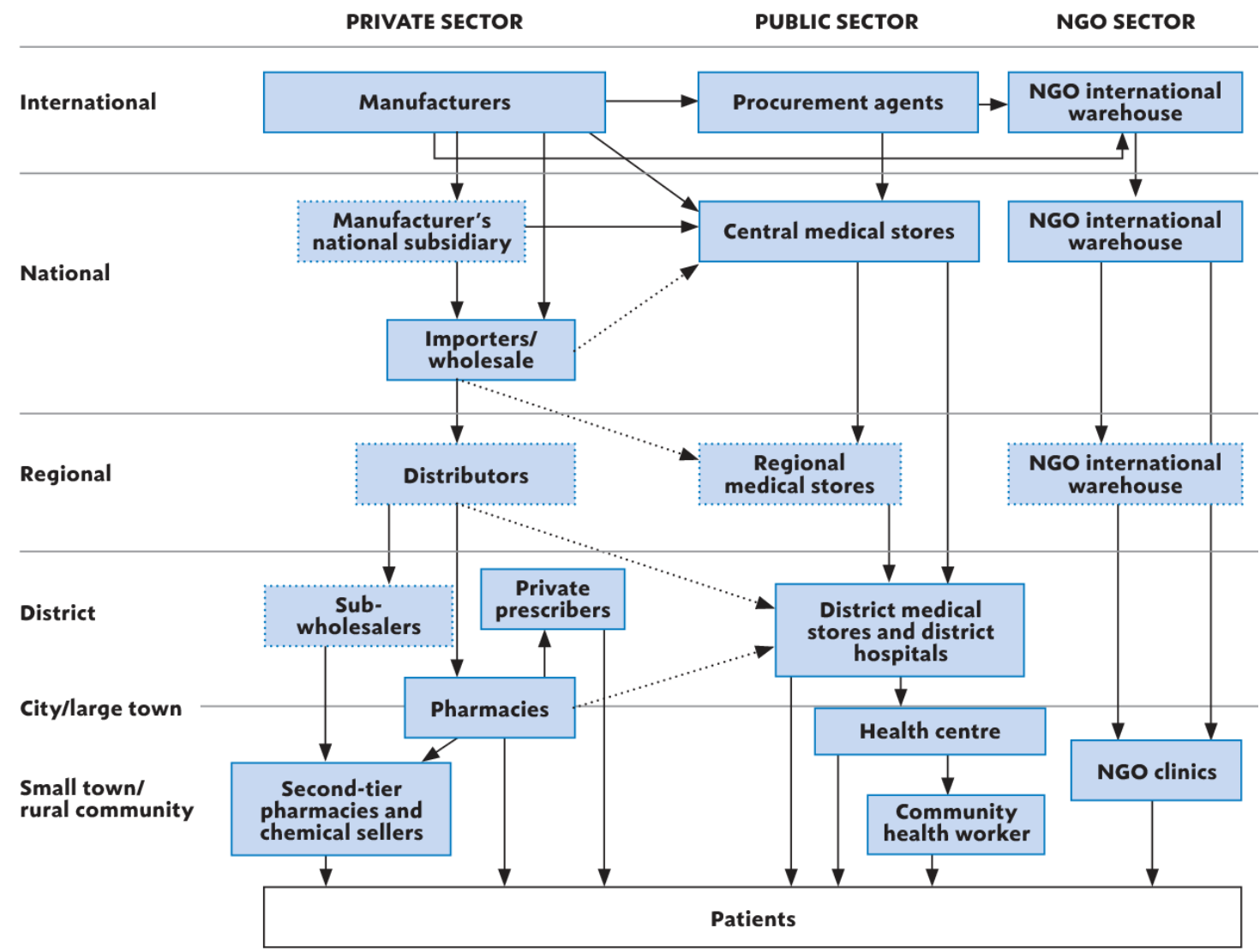

The main distribution channel of health products in LMICs is the public sector. The public supply model consists of central medical stores (CMS), a transport fleet, and a chain of medical depots at regional and district level. The CMS store the medicines and then distribute them to the health facilities. Thus, the primary objective of the CMS is to ensure uninterrupted supply of quality medicines and medical supplies to the health facilities on a regular basis. Depending on the number of health facilities in the country, the supplies might be distributed to regional or district warehouses before being transported to the health facilities. The order procedure is mostly managed by the ministry of health $(\mathrm{MOH})$. A challenge that the $\mathrm{MOH}$ faces in organizing this procedure is a lack of clarity concerning the consumption patterns, the inventory levels, and information regarding how products are managed in provisions.

Due to the typical weak infrastructure of public distribution channels, many non-governmental organizations (NGOs) have set up a separate supply chain, in parallel with the public and private supply chains. The NGO supply model consists of NGO-owned national and regional warehouses and health facilities. These NGO supply chains are generally set up for specific health programs (e.g., an ARV treatment program). 
The relevance of the private sector is limited in LMICs due to the purchasing power of the public sector. The public sector often obtains supplies from the private supply chains. In most LMICs, this is only approved in case the CMS is out of stock of the medical supply at issue (Dowling, 2011; Pisa \& McCurdy, 2019; Yadav, 2015; Yadav et al., 2011).

\section{Literature search method}

The literature review presented in this paper comprises two parts, each with a different literature search method. In the first part of the literature review, we give an overview of HIV supply chain operations in LMICs. To obtain a complete overview that is relevant for researchers and practitioners alike, we include a combination of (i) scientific and grey (i.e., websites of health and humanitarian organizations) literature, and (ii) quantitative and qualitative papers in our review. To identify relevant grey literature, the keywords in Table 1 were searched for in Google. Based on the gathered information, additional topics were investigated. Since the aim of this first part of the literature review consists of giving an overview of HIV supply chain operations in LMICs and given the wide scope of source types included (i.e., a combination of scientific and grey literature, and quantitative and qualitative papers), we do not claim to give an exhaustive overview of papers and websites. Instead, our intention consists of giving a complete overview of the main services, operations and challenges of HIV supply chains in LMICs.

Table 1: Overview of keywords used during the literature search. Each search includes a combination of three keywords (one from each column). "(-)" indicates that no keyword from that column is used.

\begin{tabular}{lll}
\hline First keyword & Second keyword & Third keyword \\
\hline HIV & Initial search & $(-)$ \\
& Distribution & Developing countries \\
Inventory management & Low- and middle-income countries \\
& Supply chain & Developed countries \\
& Prevention supply chain & \\
& Diagnosis supply chain & \\
Treatment supply chain & \\
Additional search & \\
Condom supply chain & \\
& Antiretroviral (ARV) supply chain & \\
& Antiretroviral therapy (ART) supply chain & \\
\hline
\end{tabular}

The second part of this paper is restricted to OR/OM modelling papers. To identify relevant papers, the databases Google Scholar, PubMed, Scopus, and Web of Science are searched. Because only limited $\mathrm{OR} / \mathrm{OM}$ research focusing on LMICs has been conducted, papers focusing on high-income countries are included as well (as it may be interesting to check which of the papers covering high-income countries might be applied to LMICs). A paper is included if it models and quantitatively analyses (a part of) the HIV supply chain. This means that papers applying statistical analysis, analytical optimization, heuristics, or simulation are included, while descriptive case studies are excluded from 
this second part of the literature review. The reason being that we focus on modelling papers. Furthermore, only peer-reviewed and English-language papers are incorporated. Table 1 provides an overview of the keywords that are used to search for relevant OR/OM papers. Additionally, relevant papers citing to and referred by the collected papers are included. This search method leads to a selection of $24 \mathrm{OR} / \mathrm{OM}$ papers. The last database search was conducted at the beginning of June 2020 (i.e., this study includes papers that were published up until the beginning of June 2020).

\section{Overview of HIV supply chains in low- and middle-income countries}

\subsection{HIV services}

This section presents an overview of the three types of HIV services provided through HIV programs: prevention, diagnosis and treatment.

\subsubsection{Prevention}

The main HIV prevention methods in LMICs include: (i) condom use, (ii) voluntary medical male circumcision (VMMC), (iii) pre-exposure prophylaxis (PrEP), (iv) prevention of mother-to-child transmission, and (v) harm reduction (WHO, n.d.).

\subsubsection{Condom use}

Family planning plays a major role in preventing HIV infections through condom use as the main task of family planning is to enable families to attain their desired number of children and to prevent unforeseen pregnancies. This is mainly accomplished through the use of contraceptives and fertility treatments (WHO, 2018a). The objective of the family planning supply chain is to ensure uninterrupted supply of contraceptives to family planning sites (Karim, Bieze, \& Chimnani, 2008). Since condom use is the only contraception method that protects against sexually transmitted diseases, the description of the contraceptive service delivery in this paper is restricted to condom supply chains (Center, Gunn, Asaolu, Gibson, \& Ehiri, 2016).

Condom delivery in LMICs mostly occurs for free through the public sector (see Section 2). This public provision of condoms mainly depends on donor support (Evans et al., 2018; USAID, 2019a). The United Nations Population Fund (UNFPA), USAID, and the Global Fund are the main donors of condom supply chains. The distribution of these free condoms in LMICs happens in the same way as other medical supplies (see Section 2). Hence, the CMS distribute these condoms to regional or district health settings, which in their turn transmit the condoms to condom distribution sites (Cisek \& Khomani, 2018; Sandøy et al., 2012). Condom stock-outs occur regularly in LMICs and are one of the major obstacles in HIV prevention. Responding to this problem, the U.S. President's Emergency Plan 
for AIDS Relief (PEPFAR) has set up a separate fund (i.e. the Condom Emergency Fund) to finance accelerated condom procurement in the event of stock-outs (USAID, 2019a).

\subsubsection{Voluntary medical male circumcision}

Males who participate in VMMC have a significantly lower chance of getting HIV-infected (Auvert et al., 2005; Bailey et al., 2007; Edgil et al., 2011; Gray et al., 2007). Main supplies for VMMC include medicines and tools needed for surgery. VMMC services are provided either at fixed facilities, mobile facilities, or remote facilities. Fixed VMMC facilities are usually situated within or nearby health sites. Mobile VMMC facilities generally deliver VMMC services outside health facilities. These mobile sites occur in one of the following two structures: (i) tents or (ii) vehicles. Firstly, the tents can easily be set up and moved to other sites. Secondly, the vehicles, with a fully equipped VMMC medical center inside, drive from one place to another. The length of their stay on a particular site depends on the demand for VMMC services. Remote VMMC facilities are temporarily set up sites in times of high VMMC demand (e.g., VMMC sites set up in primary care centers). Important to note is that VMMC services can only be provided by staff who have received the appropriate training to meet the final competencies determined by the WHO (USAID, 2016).

\subsubsection{Pre-exposure prophylaxis}

PrEP involves providing uninfected people at substantial risk of getting HIV-infected (e.g., key and vulnerable populations) with daily oral ARV drugs. Adherence to oral PrEP is vital for the prevention method to be effective (Case, Gomez, \& Hallett, 2019; Cremin et al., 2013; McMahon et al., 2014). However, some concerns exist about whether the introduction and expansion of PrEP does not involve too much risk. People taking PrEP drugs often neglect the importance of keeping using condoms when having sexual interaction. Also, scale-up of expensive PrEP influences the budget in LMICs, which is already limited (WHO, 2019b).

\subsubsection{Prevention of mother-to-child transmission}

Vertical transmission is responsible for most of the HIV infections among children. Prevention of mother-to-child transmission programs aim at eliminating HIV-infected newborns. An infected pregnant woman might transmit the virus to her child during pregnancy, during birth, or through breastfeeding. The chance that HIV is vertically transmitted from mother to child ranges from $15 \%$ to 45\%. Effectively treating the mother with ARV drugs (i.e., the mother is virally suppressed) can reduce this probability below 5\% (Avert, 2019b).

A sustainable prevention of mother-to-child transmission program is rather complicated as it consists of a sequence of interventions starting from prenatal care to HIV diagnosis and finally to HIV treatment for women and their newborns (Larsson et al., 2015). The start of a prevention of mother-tochild transmission program is testing pregnant women that visit prenatal health sites. However, often 
pregnant women do not visit prenatal health sites and thus are never connected with prevention of mother-to-child transmission programs (Finlayson \& Downe, 2013; Guliani, Sepehri, \& Serieux, 2014). Moreover, if pregnant women are correctly referred to prevention of mother-to-child transmission programs, integration of these programs with other programs such as early infant diagnosis (EID) and treatment is crucial for the entire prevention of mother-to-child transmission program to be effective. Unfortunately, this is often not the case implying severe health issues (e.g., untimely treatment) (Braun et al., 2011). Frequently reported stock-outs of ARV drugs and test kits make it even more challenging for prevention of mother-to-child transmission programs to be successful (Braun et al., 2011; Gils et al., 2018; Wahlfeld et al., 2019).

\subsubsection{Harm reduction}

Harm reduction is a prevention method for drug-users. Opioid substitution therapy and the use of sterile needle and syringes are part of harm reduction programs. Opioid is a variant of drugs that can be taken orally and that should not be injected. This avoids sharing needles and thus reduces the risk of HIV transmission among drug users (Avert, 2019a). A detailed discussion on opioid supply chains is out of the scope of this paper.

\subsubsection{Diagnosis}

\subsubsection{HIV testing and counselling}

The main goal of HIV testing and counselling services is to provide accurate information about the HIV-status of every person. In this way, the patients can be referred to other HIV services as soon as possible. More specifically, people that test negative on HIV should be connected with prevention programs such as VMMC or condom programming, whereas people that test positive on HIV should be referred to treatment programs (WHO, 2013).

HIV testing and counselling services mainly occur in one of the following two ways: (i) facilitybased or (ii) community-based (WHO, 2012). Facility-based HIV testing and counselling occurs in health facilities, whereas community-based HIV testing and counselling services are conducted outside health facilities (e.g., schools, workplaces, door-to-door testing, HIV testing campaigns, rural health posts, and mobile HIV testing) (Sharma, Ying, Tarr, \& Barnabas, 2015; WHO, 2013). Facility-based testing is either initiated by the test provider or by the patient itself. Conducting a routine HIV test when someone visits a clinic is defined as provider-initiated testing and counselling. If someone voluntarily visits an HIV testing and counselling site, it is classified as voluntary testing and counselling (MOH Malawi, 2016). Community-based testing and counselling services are very important since they are able to reach people who hesitate to go to health facilities (e.g., because of HIV-related stigma) to get themselves tested (WHO, 2013). 


\subsubsection{HIV diagnostics}

Diagnostics for HIV in LMICs can be categorized into three groups: (i) diagnostics for primary diagnosis of HIV, (ii) diagnostics for checking how severe HIV has already attacked the patient's immune system, and (iii) diagnostics for the follow-up of an infected person.

First, the primary diagnosis of HIV for adults is established by using either an HIV antibody test or a polymerase chain reaction test. In LMICs, an HIV antibody rapid diagnostic test (RDT) can be used in remote health settings to have people tested on HIV. RDTs are the first generation of point-of-care tests (i.e., tests that are conducted near or at the collection site) (Jani \& Peter, 2013; Stevens, Gous, Ford, \& Scott, 2014; UNITAID, 2015). The primary diagnosis of HIV for newborns younger than 18 months (i.e. early infant diagnosis - EID) happens quite differently. Every newborn of an HIV-positive woman retains HIV antibodies for several months after birth, which makes the RDT unreliable. Hence, EID is established by conducting the DeoxyriboNucleic Acid Polymerase Chain Reaction test. This expensive and more complex testing technology requires a specialized laboratory environment, and these tests are therefore mainly conducted in a centralized reference laboratory of which there are only a few in each LMIC (UNITAID, 2015). Currently, the Elizabeth Glaser Pediatric AIDS Foundation (EGPAF) and UNITAID have implemented point-of-care EID tests in nine countries with high HIVincidence (i.e., Cameroon, Côte d'Ivoire, Kenya, Lesotho, Mozambique, Rwanda, Swaziland, Zambia, and Zimbabwe). This pilot study shows that point-of-care EID significantly reduces the turnaround time (EGPAF, 2017) The turnaround time in this supply chain exemplifies the time between the collection of the blood sample and the return of the results to the tested person. However, in most LMICs, the use of point-of-care diagnostics remains challenging due to implementation barriers, such as supply chain barriers (e.g., inadequate demand forecasting, limited resources, inaccurate procurement processes, and supply uncertainty) (Engel et al., 2016; Kuupiel, Bawontuo, \& Mashamba-Thompson, 2017; Mugambi, Palamountain, Gallarda, \& Drain, 2017).

Second, after someone has been diagnosed with HIV, it is necessary to check to what extent the virus has already attacked the body's immune system to treat the patient as effectively as possible (UNITAID, 2015). Once a person is infected with HIV, the virus starts demolishing the body's CD4 cells. The amount of these cells in someone's body indicates the status of the body's immune system (Ford et al., 2015; Phillips et al., 1991). Although some point-of-care tests for CD4 count exists, the CD4 test is mainly conducted in laboratory settings.

Last, another important use of HIV diagnostics is to check whether ARV treatment is successful. A plasma viral load test measures the amount of HIV particles in someone's blood. The lower the viral load in the blood, the less HIV is in the blood, and the better the ARV therapy is working. In LMICs, the use of plasma viral load tests is challenging because of their expensiveness. Plasma has to be separated from the blood sample to be able to conduct a plasma viral load test. This separation can only be done in specialized reference laboratories (UNITAID, 2015). Recent development of point-of-care viral load tests is very promising. Point-of-care viral load tests require less training of health care 
workers, eliminate the high turnaround time, and improve adherence rates. However, before these new technologies can be implemented extensively in LMICs, field studies have to be done on the efficacy of point-of-care viral load tests (Meloni et al., 2019).

\subsubsection{The laboratory network for HIV diagnosis}

The laboratory network for HIV diagnosis in LMICs consists of three main layers as shown in Figure 2. The lowest level constitutes of decentralized health settings where most people initially get in contact with HIV services (UNITAID, 2015). Simple laboratories are present in which point-of-care tests are conducted (Stevens et al., 2014). The higher up the pyramid, the more complex test technologies (e.g., viral load testing and polymerase chain reaction) are present and the more highlyskilled staff are required.

Figure 2: Tiered laboratory structure for HIV diagnostic services in LMICs (based on Parekh et al. (2018) and UNITAID (2015)).

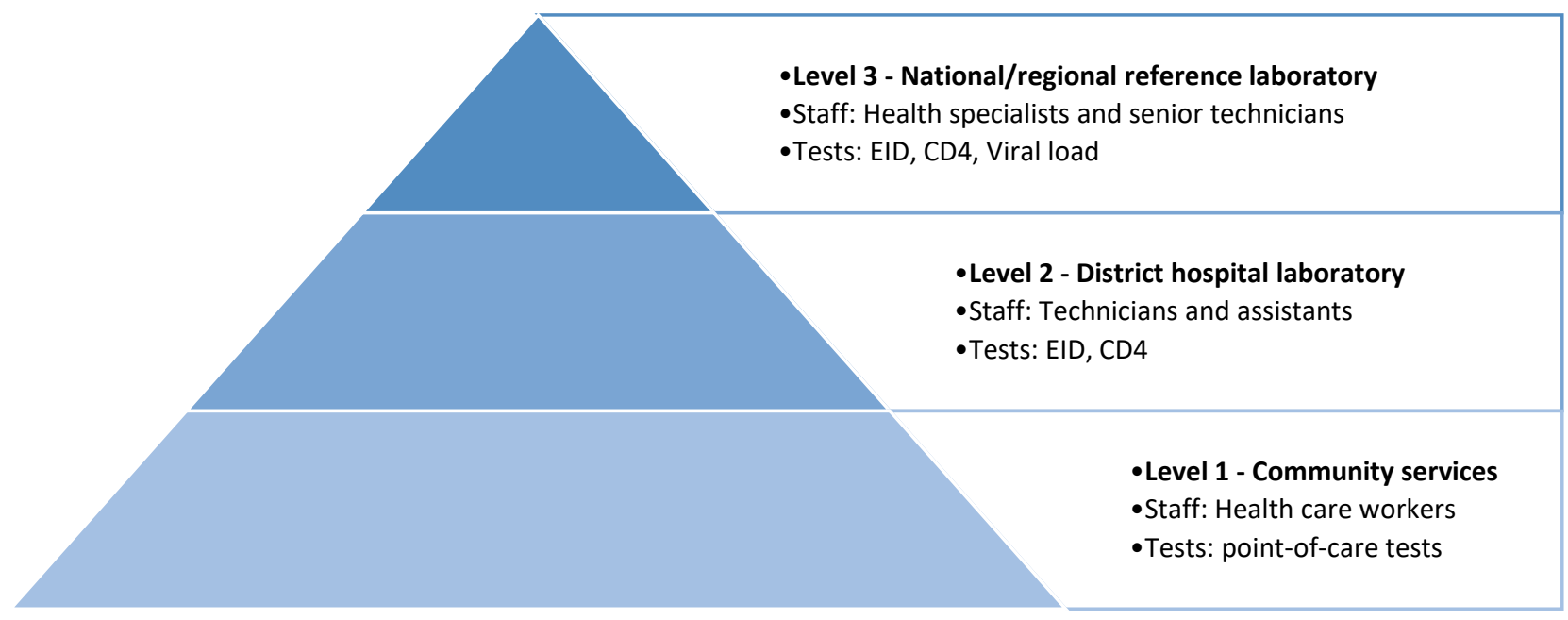

\subsubsection{Treatment}

HIV is treated through the administration of ARV drugs. Standard treatment involves a daily dose of a combination of different ARV drugs. Although one can never be cured from HIV, treatment with ARV drugs reduces the number of virus particles in the blood (i.e., the viral load) to such an extent that it is no longer transmissible (i.e., treatment as prevention) nor detectable. People living with HIV receiving accurate treatment have the same life expectancy as uninfected people. Crucial in HIV treatment is treatment adherence (i.e., taking treatment timely) since treatment interruption may lead to HIV drug resistance (UNAIDS, n.d.).

\subsection{Operations}

In this section, we give an overview of two types of operations related to HIV programs: the supply chain of HIV commodities (Section 4.2.1) and the sample referral network (Section 4.2.2). 


\subsubsection{Supply chain of HIV commodities}

The supply chain of HIV commodities includes the procurement and distribution of products for HIV prevention, diagnosis, and treatment. This section presents the main stakeholders of this supply chain and describes the different activities involved in procuring and distributing HIV commodities. Although the information is based on a paper focusing on ARV drugs (i.e., Ripin et al. (2014)), this description applies to prevention and diagnostic commodities as well since nowadays more and more LMICs are integrating the supply of the three types of HIV services (i.e., prevention, diagnosis, and treatment) into one unified HIV supply chain (AVAC, 2019; USAID, 2019e, 2019c).

\subsubsection{Main stakeholders}

The supply chain aims to transfer HIV commodities from manufacturers to patients (Ripin et al., 2014). The main stakeholders in this supply chain consist of manufacturers, beneficiaries, funders, and operating agents.

First, the start of the HIV supply chain includes manufacturers that produce HIV commodities. For ARV drugs, the drug manufacturers can be split up into two groups. Manufacturers that introduce a new branded drug are called originators. Contrarily, manufacturers that produce medicines with the same substances as an originally marketed branded drug are called generic manufacturers. The ARV manufacturers that produce drugs for LMICs are generally generic. These manufacturers make use of a lean manufacturing model that fits well into the markets of LMICs asking for large volumes and low prices.

Second, the countries and their chain of associates that receive the commodities are defined as beneficiaries. The responsibilities of the beneficiaries are situated both on the upstream and downstream features of the supply chain. On the one hand, beneficiaries decide on the ordered quantities and the timing of the order placement. Also, predicting the lead time is the responsibility of the beneficiaries. On the other hand, the task of the beneficiaries also consists of controlling the in-country supply chain (i.e., storing the HIV commodities at a CMS, shipping the commodities to regional or district facilities, and finally to the health facilities).

Third, the supply chain is financed by donor organizations. Recently, LMICs are increasingly becoming both the recipient and the funder of this supply chain. Due to, among others, international financing arrangements with the World Bank, LMICs can either fully or partially rely on domestic funding for the acquisition of health supplies. Countries that do not participate in these international agreements, obtain money from donors. The two biggest and best known donors are PEPFAR and the Global Fund. Depending on which donor a country is supported by, a different supply chain model is applied. Beneficiaries that receive money from the Global Fund usually operate under the distributed, country-led supply chain model. Under this model, countries can manage the supply chain themselves. A drawback of this model is that countries will decide on their supply chain partners independently from each other, thereby eliminating the cost benefits of a more integrated model. Meanwhile, countries 
funded by PEPFAR operate under a fully integrated supply chain model. In this case, the funder itself manages the supply chain and settles agreements with supply chain partners.

Last, the operating agents are in charge of two main tasks: (i) moving the commodities from the manufacturers towards the beneficiaries and (ii) making sure that the money of the funders is paid to the manufacturers. The operating agents generally place and track orders, select suppliers, and control the quality of the commodities before shipment. The main operating agents involved in the supply chain are procurement agents, customs, and freight forwarders. The procurement agents include national (e.g., the Zambia Public Procurement Authority) and international organizations (e.g., the United Nations Children's Fund (UNICEF), Médecins Sans Frontières (MSF), and the International Dispensary Association (IDA) Foundation). Since the tasks of the operational agents strongly depend on a trade agreement between the funders and the beneficiaries, the organization of this supply chain might alter strongly depending on the different trading conditions.

\subsubsection{Operational processes}

The supply chain for HIV commodities consists of six main operational processes (Ripin et al., 2014):

1. The country requests for HIV commodities. The number of medicines needed is determined by the country itself. This quantification must happen timely to prevent future stock-outs.

2. The operating agent selects a suitable manufacturer and orders the required amount.

3. Once the order is accepted and executed by the manufacturer, a quality check is performed, after which the commodities are prepared for transport. Most donor organizations and countries obligate this quality check. However, a few countries do not require the quality check and skip this third step.

4. The HIV commodities are distributed to the receiving country. In general, these shipments occur via sea or air transport.

5. The goods have to pass customs approval. Once the approval has been granted, the HIV commodities are stored in a so-called 'first point of delivery', which is usually the CMS. The customs approval often takes a long time and might result in longer lead times.

6. The final step of this supply chain consists of distributing the commodities at country level towards the patients in need. The commodities have to be transported from the CMS towards local facilities. In countries where there are many health facilities, there might be warehousing points (i.e., regional warehouses) in between the CMS and the health facilities, as also indicated in Section 2 (Minior et al., 2017; Sekhri, 2006; Yadav et al., 2011).

Recently, more and more use is being made of third-party logistics (3PLs) to support HIV supply chains and to tackle challenges related to the supply of HIV commodities. 3PLs are deployed for both the procurement of commodities, the management of warehouses, and the distribution of commodities (Faruna, Akintunde, \& Odelola, 2019; Ministry of Health Malawi, 2014; USAID, 2019d). 
Although the supply model of VMMC, condoms and ARV drugs is similar to that of other HIV commodities, some special features concerning the supply of these products are discussed in the literature. First, USAID's Procurement and Supply Management program (i.e., one of the projects of USAID's Global Health Supply Chain Program) finances a vendor-managed inventory system for the condom and VMMC supply chains as a solution for the long lead time. An agreement has been set up between USAID and three producers of prevention supplies (i.e., two producers of VMMC kits and one condom procurer). Under a vendor-managed inventory system, the seller (i.e., the producers of prevention supplies) has full responsibility for maintaining an agreed inventory level of the goods (i.e., prevention supplies) solely for the client (i.e., USAID). A major advantage of this system is that urgently required supplies can be transported in a period of eight to ten days from the depots in high-income countries to the recipient LMIC. Furthermore, there is no need to pre-purchase prevention supplies in LMICs, eliminating high storage costs and expired supplies (USAID, 2019f).

Second, the importance of making accurate demand forecasts, performing quality checks, ensuring decent storage conditions at every part of the supply chain, and following up on the drug inventory levels in the ARV supply chain is highlighted in the literature. In the past, it has been common for a local facility to encounter medicine shortages, while there is sufficient stock available at the national level. Stock-outs of ARV drugs have serious implications for the health prospects of patients as treatment interruption can lead to HIV drug resistance (Minior et al., 2017). As a response to this emerging problem, the World Health Organization (WHO) recommends LMICs to secure a buffer stock for ARV drugs at the national level (i.e., at the CMS) (WHO, 2018b). Next to this, the WHO intends to establish warning systems to prevent local and national stock-outs (Gils et al., 2018). The movement of ARV drugs currently takes two to six months from the order date until customs clearance is granted in the recipient LMIC. Another four to six months go by before the drugs are moved from the central warehouse to the ARV drug facilities (Minior et al., 2017).

\subsubsection{Sample referral network}

Crucial in HIV service delivery is the timely and adequate transportation of specimens from collection sites to the closest suitable laboratory and the timely communication of the results from the laboratories to the health centers. The network of activities that is used to transport the specimens to the laboratories, subsequently test the samples, and finally deliver the results is defined as the sample referral network. A commonly used performance measure for the well-functioning of sample referral networks is the turnaround time (Kebede et al., 2016; Shiferaw \& Yismaw, 2019; UNITAID, 2015).

Jónasson, Deo, and Gallien (2017) define the turnaround time as the sum of the pre-processing time, the transportation time, the lab cycle time, and the post-processing time. After a care provider has taken a blood sample, the sample needs to be transported to the appropriate laboratory as soon as possible. The transportation mode that is used to transfer the samples to the laboratories depends on several factors including the facility location, the distance from the collection site to the laboratory, the 
condition of the roads in the area, and the local environment. Common transportation types in LMICs for sample transportation are motorcycles, cars, public transport systems, and recently also drones (Nichols et al., 2018; USAID, 2019b). Unfortunately, it may take some time before the samples leave for the laboratory. This may happen because there is no proper transportation mode available at that time. Consequently, one has to wait until, for example, someone from the care staff of the remote site travels to a more urban area. The time a sample has to wait to be transported is defined as the preprocessing time. As soon as a transportation medium becomes available, the samples that are waiting to be transported are picked up. The time it takes for the samples to arrive at their destination is called the transportation time. Because many of the test devices are very expensive, one aims to test as many samples as possible at the same time. Consequently, the samples often have to wait for a while in the laboratory until there are enough samples to test a full batch. After the samples have been tested by the test device, the results are reviewed, entered into a computer and sent back to the site where the patient was initially tested. The time from the moment the samples arrive in the laboratory until the results are checked and sent back to the collection site is called the lab cycle time. As soon as the collection site receives the test results, the patient should return to the site for a follow-up meeting. The return of results usually happens through mobile technologies or sporadically using the same transport medium as the untested specimens. The time that elapses between sending the results until the patient knows his result is defined as the post-processing time (UNITAID, 2015).

In addition to supporting the supply chain of HIV commodities, the use of 3PLs can support sample referral networks. For example, Adeiye et al. (2019) conducted a case study in Nigeria to investigate the impact of using 3PLs for transporting viral load samples from collection sites to laboratories and subsequently deliver the result back to the collection site. The study reported that the use of 3PLs in this case significantly lowered the turnaround time and thereby reducing the number of rejected samples. Furthermore, testing results were delivered much faster.

As a part of their Procurement and Supply Management program (i.e., a project of the USAID Global Health Supply Chain Program), USAID introduced the use of drones in the transportation of blood samples (for viral load, EID and tuberculosis testing) and the result delivery in Malawi. These drones can serve collection sites that were not covered before because of their remoteness. The pilot study conducted in Malawi shows that the use of this transport mode in the diagnosis supply chain can result in lower turnaround time, improving people's health prospects. The future use of drones in this context depends on the availability of funds (USAID, 2019b) and drone regulations (Fonjungo et al., 2017).

\subsection{Challenges}

Providing universal access to HIV services might be one of the most ambitious tasks in global health programs (WHO, 2016). HIV supply chains in LMICs face several challenges that hinder the scale-up of HIV services. The main challenges faced by organizing HIV supply chains as reported in 
the literature include: (i) supply uncertainty and stock-outs, (ii) limited human resources, (iii) limited shelf life of HIV supplies, (iv) poor laboratory infrastructure and services, (v) demand forecasting, (vi) weak sample referral networks, (vii) limited access to HIV services, and (viii) limited financial resources.

\subsubsection{Supply uncertainty and stock-outs}

Supply uncertainty and stock-outs of HIV commodities (e.g., condoms, test kits, and ARV drugs) are reported as being the main challenges for the scale-up of HIV services in LMICs. Several studies have shown that LMICs often encounter stock-outs of crucial HIV commodities (Berhanemeskel, Beedemariam, \& Fenta, 2016; Gabriel \& Tafesse, 2017; Hwang et al., 2019; Kuupiel, Tlou, Bawontuo, Drain, \& Mashamba-Thompson, 2019; Layer et al., 2014; Mutemwa et al., 2013; Wagenaar et al., 2014) Well-managed logistics management information systems (LMIS) can significantly reduce the number of stock-outs of HIV supplies in health facilities. Data gathered through LMIS assist decision-makers in determining whether the supplies that are currently available are sufficient to serve the demand (Obeagu, 2017). However, LMIS are often inadequately implemented in LMICs (Desale, Taye, Belay, \& Nigatu, 2013) and many HIV sites still depend on paper-based LMIS (Minior et al., 2017). Studies conducted in Nigeria further stress the importance of accurate data management to prevent stock-outs (Ibegbunam \& McGill, 2012; Itiola et al., 2019). Furthermore, poor inventory management in the regional and district warehouses also contributes to the occurrence of stock-outs (Raja \& Mohammed, 2004).

\subsubsection{Limited human resources}

The shortage of health care workers is an additional difficulty for the health system in LMICs, which is already unstable (Naicker, Plange-Rhule, Tutt, \& Eastwood, 2009). For example, only 2 doctors per 100000 inhabitants are present in Malawi while the WHO standard requires 23 doctors per 100000 inhabitants. The main reasons for these low doctor to inhabitant rates are: low wages resulting in highly-skilled health care workers to emigrate, HIV infection among health care workers which causes them to fall sick and not being able to go to work, poor working environment, and low ambition (WHO, 2010; Zachariah et al., 2009). An interview-based study conducted in Kenya affirmed their salary to be one of the main reasons for the dissatisfaction and emigration of health care workers (Mutemwa et al., 2013).

A serious consequence of these shortages is that people have to wait a long time at the health facilities before being helped, with the result that they return home without receiving HIV services. This is reported as one of the main causes of non-adherence to ARV therapy (Tafuma et al., 2018). A possible solution for this problem is task shifting (i.e., nurses are trained to administer ARV treatment instead of doctors who now have a supervising role). The implementation of a task-shifting model in 
multiple African countries (e.g., Botswana, Lesotho, and Mozambique) turned out to be successful (Zachariah et al., 2009).

\subsubsection{Limited shelf life}

Due to the limited shelf life of HIV test kits and ARV drugs, their lead times and buffer stocks should be controlled accordingly. Lead times should be shortened as much as possible and buffer stocks cannot be kept too high (Marlink \& Teitelman, 2009; Xiong et al., 2008). Furthermore, these supplies have to be stored properly to avoid wastage (e.g., provide all packages with an expiration date) (Raja \& Mohammed, 2004).

Ripin et al. (2014) further argue that given the long time frame between ordering and receiving ARV drugs (see Section 4.2.1.2), countries have implemented strict standards concerning the shelf life of the drugs. Usually, receiving countries require the shelf life of the drugs at the moment of arrival to be around $77 \%$ of the total shelf life. The total shelf life of test kits and ARV drugs is usually limited to two years and can even be restricted to six months (Marlink \& Teitelman, 2009). The main disadvantage of this requirement is that drug manufacturing facilities hold only limited or no inventory. This means that manufacturers will delay production until they are sure that demand is sufficiently high for the production of a full batch. This, in turn, results in higher chances of delays and stock-outs, especially in countries requesting small amounts of drugs (Ripin et al., 2014).

\subsubsection{Poor laboratory infrastructure and services}

High-quality laboratory infrastructure and services are essential for HIV programs to be effective. Poor laboratory infrastructure and services in LMICs are mainly due to insufficient space, malfunctioning testing machines because of insufficient maintenance, undertrained workforce, insufficient storage area, uncertain supply of water and electricity, and stock-outs and expiration of supplies (Ibegbunam and McGill, 2012; Justman et al., 2009; Xiong et al., 2008).

\subsubsection{Demand forecasting}

Demand forecasting of HIV supplies (e.g., condoms, test kits, and ARV drugs) requires efficient forecasting systems, which are often fragile in LMICs. Countries have difficulties in quantifying the supplies that are needed because of lacking information about consumption patterns and stock levels. Furthermore, a shortage in trained staff with knowledge about forecasting systems also contributes to difficulties in demand forecasting. Inaccurate demand forecasting is a main reason for stock-outs and wastage of HIV supplies (Galárraga et al., 2007; Sekhri, 2006). For example, the amount of required ARV drugs is estimated by the recipient country. On the one hand, if the country's estimates are too low (i.e., under-forecasting), stock-outs of ARV drugs are likely to occur and emergency orders are required which significantly increases costs since these emergency orders have to be delivered through 
highly expensive air transport. In comparison, in case the right amount of drugs is ordered on time and no emergency orders are necessary, the drugs can be delivered through ocean transport which results in cost savings of more than 50\% compared to air deliveries. On the other hand, if the country's estimates are too high (i.e., over-forecasting), the country faces excessive amounts of stock which may result in drugs to lapse before usage, increasing costs and wastage (Larson, Burn, Minnick-Sakal, Douglas, \& Kuritsky, 2014).

\subsubsection{Weak sample referral networks}

A major issue is the weakness of sample referral networks. Two main challenges are related to the sample referral network: (i) cold chain requirement and (ii) poor logistic infrastructure. Firstly, whole blood samples require cold chain transportation. This implies that the blood samples should be packed in cool boxes before transportation. If the temperature of the blood samples is not controlled accordingly, these samples will be of bad quality and the laboratory might reject them. Another sample needs to be drawn resulting in several issues such as higher turnaround time and postponement of treatment initiation. Secondly, the absence of decent roads, poorly maintained vehicles, and roads in poor condition often cause problems in specimen transport, such as higher turnaround time or damaged samples (Fonjungo et al., 2017; Nichols et al., 2018; Raja \& Mohammed, 2004). For example, Shiferaw and Misganaw (2020) examined the performance of EID referral networks in Ethiopia. The turnaround time of the tests was about 30 days, severely exceeding the target of 10 days.

\subsubsection{Limited access to HIV services}

Limited access to HIV services (i.e., prevention, diagnosis and treatment) is a major challenge for HIV supply chains. This paper defines access as the opportunity for anyone in need of HIV services to access it. Several researchers have reported gaps in the accessibility of HIV services. Sandøy et al. (2012) argue that condoms, being the main HIV prevention method, should be available at meeting places (e.g., bars and hotels) where one might meet a new sex partner. However, research has shown that in multiple meeting places no condoms were available (Sandøy et al., 2012). Furthermore, approximately $50 \%$ of people living with HIV were unaware of their HIV status in 2015 implying deficiencies in the accessibility of HIV diagnostic services (Shrestha, Philip, Shewade, Rawal, \& Deuba, 2017).

HIV-related stigma is a main contributor to limited access to HIV services (i.e., people are ashamed to visit health posts) (Bond, Chase, \& Aggleton, 2002; Chesney \& Smith, 1999; Kalichman \& Simbayi, 2003; Layer et al., 2014; Tafuma et al., 2018). Also, many researchers have reported on the limited access to ARV treatment due to transportation costs (Hardon et al., 2007; Mills et al., 2006; Mshana et al., 2006; Mukherjee, Ivers, Leandre, Farmer, \& Behforouz, 2006; Tuller et al., 2010; Weiser et al., 2003). People living in LMICs, and especially in remote neighborhoods, often have a restricted budget 
that is not sufficient to pay for the transportation costs to ARV facilities (i.e., people run out of budget after having paid for essentials like food and places to live) (Tuller et al., 2010). Moreover, field research conducted by Layer et al. (2014) in Tanzania revealed the distance to health facilities to be one of the main obstacles to achieving universal access to HIV services.

\subsubsection{Limited financial resources}

Limited financial resources at the national level pose a challenge for LMICs (Xiong et al., 2008). LMICs suffer from insufficient capital as the need for funding is larger than what is available (Lasry et al., 2007; UNAIDS, 2014). Harries et al. (2016) argue that a reason for this might be inefficient usage of financial resources. More specifically, funds for HIV programs are probably used for other than HIVrelated purposes. Accurate tracking of resource spending might resolve this problem (Harries et al., 2016).

\section{Classification and discussion of OR/OM papers}

\subsection{Classification criteria}

The classification of the selected OR/OM literature is based on seven classification criteria: decision level, methodology, type of HIV service modelled, challenges covered, performance measures, real-life applicability, and countries covered.

Decision level. The literature is classified as addressing either strategic, tactical, or operational decisions. Strategic decisions involve the procurement and distribution of resources to be employed over a long period (e.g., resource allocation). Tactical decisions are planned towards achieving and executing the strategic level decisions and have a medium-term impact (e.g., transportation modes). Last, operational decisions include tasks that must be performed over a short period (e.g., demand forecasting).

Methodology. We classify the OR/OM literature into four types of methodology: statistical analysis, analytical optimization, heuristics, and simulation. First, statistical analysis involves the use of statistical techniques to quantitatively determine probabilistic or statistical relationships. Second, when applying an analytical optimization method, an optimal solution for the problem is found. Third, heuristics can be used if optimization methods are not able to solve the problem in a timely manner or do not find a feasible solution. The outcome is an approximation of the optimal solution. Last, a simulation model tries to imitate a real-life situation by incorporating all relevant sources of uncertainty to accurately predict its performance.

Type of HIV service modelled. As explained in Section 4, HIV services can be split up into three main types: prevention, diagnosis, and treatment. Hence, the type of HIV service that is modelled in each of the selected OR/OM papers is indicated. 
Challenges covered. HIV supply chains in LMICs face a large number of challenges (Section 4.3). The OR/OM papers are classified based on the challenges covered in order to investigate to what extent these challenges have been modelled or focused on in OR/OM literature (Table 2).

Table 2: Challenges of HIV supply chains in LMICs.

\begin{tabular}{|c|c|c|c|c|c|c|c|c|}
\hline \multirow[t]{2}{*}{ Type of HIV service } & \multicolumn{8}{|c|}{ Challenges } \\
\hline & 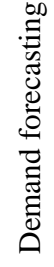 & 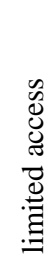 & 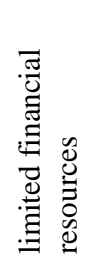 & 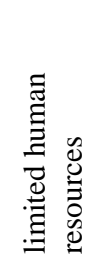 & 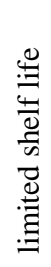 & 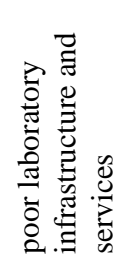 & 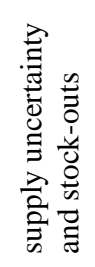 & 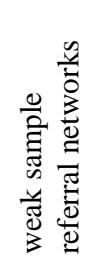 \\
\hline Prevention & $\mathrm{x}$ & $\mathrm{x}$ & $\mathrm{x}$ & & & & $\mathrm{x}$ & \\
\hline Diagnosis & $\mathrm{x}$ & $\mathrm{x}$ & $\mathrm{x}$ & $\mathrm{x}$ & $\mathrm{x}$ & $\mathrm{x}$ & $\mathrm{x}$ & $\mathrm{x}$ \\
\hline
\end{tabular}

Performance measures. Three types of performance measures are considered: economic, technological, and value performance measures (Vandaele \& Decouttere, 2013). Economic performance measures are related to profits and costs. The technological aspect involves the flow of resources through the supply chain. Finally, value performance measures focus on health, societal, ethical, and environmental outcomes.

Real-life applicability. We classify the OR/OM literature based on three degrees of applicability. The first and lowest degree of applicability is the use of real-life data. This real-life data can be obtained through databases, field studies, interviews, surveys, and observations. Second, the engagement of stakeholders implies the second degree of applicability. If the proposed models or solution are discussed at least once with one stakeholder, we indicate that stakeholder engagement exists. In case a paper does not indicate whether stakeholder involvement was present, the paper is classified as not incorporating the second degree of real-life applicability. The final and highest degree of applicability is the implementation or use of the results beyond the considered research. In this case, the research has an impact on the operations in practice. This degree is identified by case and pilot studies that were conducted in response to the findings of the OR/OM study. In case an OR/OM paper signifies the motive of the stakeholders to implement the outcome into practice, the paper is classified as including the third degree of real-life applicability. If a selected paper incorporates the third degree of real-life applicability, we assume that the second degree (i.e., stakeholder involvement) is also present.

Countries covered. To suggest future research and case studies, OR/OM papers are distinguished based on the countries covered in the articles. First, an overview is given of the countries covered. 
Second, we investigate whether the models developed in papers that focus on high-income countries can be applied to LMICs.

\subsection{Classification results}

Even though many researchers stress the importance of enhancing HIV supply chains, the number of OR/OM papers that cover this matter is rather low: 24 OR/OM papers focus on HIV supply chains. Table 3 classifies the papers according to the journal they are published in. The journals Health Care Management Science and Medical Decision Making published a substantial percentage (i.e., approximately 33\%) of the relevant OR/OM papers. Other selected papers are spread over the different journals.

Table 3: Classification based on journal.

\begin{tabular}{ll}
\hline Journal & Frequency \\
\hline Health Care Management Science & 4 \\
Medical Decision Making & 4 \\
European Journal of Operational Research & 2 \\
Journal of the Operational Research Society & 2 \\
Operations Research & 2 \\
Production and Operations Management & 2 \\
AIDS & 1 \\
Information Systems and Operational Research & 1 \\
Journal of Public Health Management \& Practice & 1 \\
Manufacturing \& Service Operations Management & 1 \\
Mathematical Biosciences and Engineering & 1 \\
Operations Research for Health Care & 1 \\
PLoS ONE & 1 \\
PLoS MEDICINE & 1 \\
Total & 24 \\
\hline
\end{tabular}

Figure 3: Number of publications by publication year. 2020 includes articles published before the beginning of June 2020.

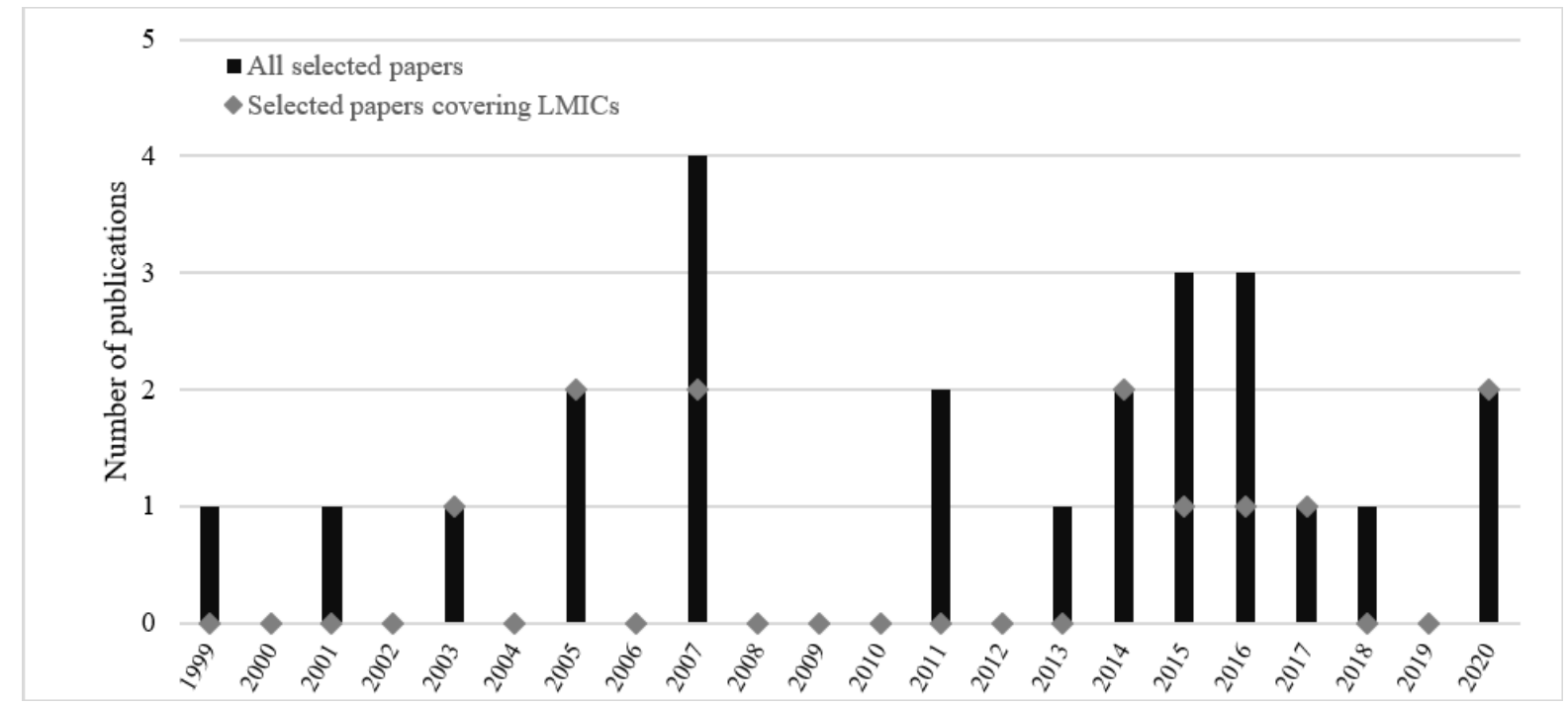

As can be derived from Figure 3, approximately $63 \%$ of the selected papers has been published in the last ten years. Moreover, more than half of the selected papers focusing on LMICs have been 
published in the last six years. It is clear that HIV supply chains are getting increased attention in $\mathrm{OR} / \mathrm{OM}$ research.

\subsubsection{Decision level}

A first observation from Table 4 is that almost all of the selected papers focus on the strategic decision level. The strategic decision that is considered most is how to distribute available funds among different HIV prevention programs and different populations that are mainly affected by HIV (Earnshaw, Hicks, Richter, \& Honeycutt, 2007; Kassa, 2018; Kessler et al., 2013; Lasry et al., 2007; Lasry, Sansom, Hicks, \& Uzunangelov, 2011; Malvankar \& Zaric, 2011; Rauner, Brailsford, \& Flessa, 2005; Richter, Brandeau, \& Owens, 1999; Vieira, Harper, Shahani, \& De Senna, 2003; Yaylali et al., 2016; Zaric \& Brandeau, 2001a, 2007). Optimizing this resource allocation problem on a more detailed level, Kassa (2018), Lasry et al. (2007), and Malvankar and Zaric (2011) take into account the different levels at which decisions about the allocation of funds are made. More specifically, the upper-level decision, in this case, is the allocation of funds from centralized funding organizations (e.g., the Global Fund) to different countries. Subsequently, the lower-level decision includes the allocation of these funds from country-level to regional-level. Rauner et al. (2005) and Vieira et al. (2003), in turn, specifically focus on the prevention of mother-to-child transmission programs.

Table 4: Classification based on decision level.

\begin{tabular}{ll}
\hline Decision level & Reference \\
\hline Strategic & Alistar et al. (2014); Barrow et al. (2020); de Vries et al. (2020); Deo and Sohoni (2015); \\
& Earnshaw et al. (2007); Jónasson et al. (2017); Juusola and Brandeau (2016); Kassa \\
& (2018); Kessler et al. (2013); Kok et al. (2015); Lasry et al. (2007); Lasry et al. (2011); \\
& Malvankar and Zaric (2011); McCoy and Johnson (2014); Núñez Ares et al. (2016); \\
& Rauner et al. (2005); Richter et al. (1999); Vieira et al. (2003); Wilson and Blower (2005); \\
& Yaylali et al. (2016); Zaric and Brandeau (2001a); Zaric and Brandeau (2007). \\
\hline Tactical & Deo et al. (2015). \\
\hline Operational & Galárraga et al. (2007). \\
\hline
\end{tabular}

In addition, Alistar, Long, Brandeau, and Beck (2014) and Juusola and Brandeau (2016) determine the allocation of a budget among a range of prevention and treatment programs. Barrow, Fairley, and Brandeau (2020), in turn, decide on the optimal investment in different interventions to maximize the number of patients achieving viral suppression. Wilson and Blower (2005) consider the complex decision of allocating limited ARV medicines among health care facilities when the number of people in need of treatment surpasses the supply of ARV medicines. Kok et al. (2015) address the optimal distribution of resources among different HIV diagnosis programs. The allocation of treatment resources among different periods is dealt with by McCoy and Johnson (2014) where the treatment budget has to be allocated in such a way that patient adherence is maximized. Jonassón, Deo, and Gallien (2017) decide on the optimal assignment of health facilities to laboratories for EID. Additionally, they aim to optimize the allocation of limited laboratory capacity to different locations. 
Deo and Sohoni (2015) optimize the allocation of point-of-care diagnostics to health facilities. De Vries, van de Klundert, and Wagelmans (2020) and Núñez Ares, de Vries, and Huisman (2016) focus on the location of new health facilities providing HIV services (e.g., condom provision and testing). De Vries et al. (2020) also consider which HIV services should be available at these new facilities. It is interesting to note that all of these decisions relate to limited financial and material resources that LMICs typically have to deal with.

Another insight from Table 4 is that the selected papers addressing tactical or operational decisions are scarce. At the tactical decision level, Deo, Rajaram, Rath, Karmarkar, and Goetz (2015) determine the optimal staffing levels in different health facilities and the optimal testing policy (e.g., only test people at high risk of getting HIV-infected). Furthermore, only one of the selected papers focuses on the operational level: Galárraga et al. (2007) estimate the future demand for ARV drugs.

\subsubsection{Methodology}

The main methodology that is used in the selected papers is analytical optimization (Table 5). We distinguish between two subcategories of analytical optimization methods: (i) optimization models and (ii) mathematical models. Firstly, optimization models consist of an objective function subject to multiple constraints that restrict the decision variables, and are solved using specialized software (e.g., CPLEX). The optimization models developed in the selected papers include linear programming (Earnshaw et al., 2007; Juusola \& Brandeau, 2016; Kassa, 2018; Malvankar \& Zaric, 2011; McCoy \& Johnson, 2014; Yaylali et al., 2016; Zaric \& Brandeau, 2007), non-linear programming (i.e., Alistar et al., 2014; Kok et al., 2015; Lasry et al., 2011, 2007; Richter et al., 1999), mixed-integer programming (de Vries et al., 2020; Deo \& Sohoni, 2015; Jónasson et al., 2017; Núñez Ares et al., 2016), quadratic programming (McCoy \& Johnson, 2014), non-linear integer programming (Barrow et al., 2020), and non-convex programming (Kassa, 2018). Secondly, if the paper derives the optimal solution through mathematical analysis, the paper utilizes mathematical modelling. Only one of the selected papers uses this approach (i.e., Wilson \& Blower, 2005).

Table 5: Classification based on methodology.

\begin{tabular}{ll}
\hline Methodology & Reference \\
\hline Analytical optimization method & Alistar et al. (2014); Barrow et al. (2020); de Vries et al. (2020); Deo \\
& and Sohoni (2015); Earnshaw et al. (2007); Jónasson et al. (2017); \\
& Juusola and Brandeau (2016); Kassa (2018); Kok et al. (2015); Lasry \\
& et al. (2007); Lasry et al. (2011); Malvankar and Zaric (2011); Núñez \\
& Ares et al. (2016); McCoy and Johnson (2014); Richter et al. (1999); \\
& Wilson and Blower (2005); Yaylali et al. (2016); Zaric and Brandeau \\
& (2007). \\
\hline Heuristics & Deo and Sohoni (2015); Deo et al. (2015); Kok et al. (2015); Lasry et \\
& al. (2007); Zaric and Brandeau (2001a). \\
\hline Simulation & Deo and Sohoni (2015); Barrow et al. (2020); Jónasson et al. (2017); \\
& Kessler et al. (2013); Kok et al. (2015); Rauner et al. (2005); Vieira et \\
& al. (2003). \\
\hline Statistical analysis & Galárraga et al. (2007). \\
\hline
\end{tabular}


As can be derived from Table 5, fewer papers use simulation as a modelling approach. The selected papers either use simulation (i) in combination with analytical optimization and/or heuristics or (ii) as the main modelling method. Combining simulation with analytical optimization, Deo and Sohoni (2015) and Jónasson et al. (2017) use simulation to verify the solution of the optimization model. In addition, Kok et al. (2015) simulate four different scenarios in which allocations have to take place depending on the decisions of policy-makers. Subsequently, they optimize these four scenarios using analytical optimization and heuristics. Barrow et al. (2020), in turn, develop a stochastic patient flow model to validate the solution of the resource allocation model. Three selected papers use simulation as the main method to decide on optimal intervention strategies in HIV prevention programs. Rauner et al. (2005) and Vieira et al. (2003) both compare different scenarios in which several combinations of interventions for preventing mother-to-child transmission are simulated. Kessler et al. (2013) use a scenario-based analysis to compare the impact of different interventions on the number of infections averted.

Five of the selected papers use heuristics (Table 5). Deo et al. (2015) develop a non-linear mixedinteger program for their planning problem. However, none of the used solvers (i.e., BARON and DICOPT using the NEOS server) was able to generate a feasible solution. Consequently, to solve the problem, Deo et al. (2015) develop fixed and variable staffing heuristics. Deo and Sohoni (2015) discuss two heuristics to solve their model (i.e. the largest volume heuristic and the minimum turnaround time heuristic), in addition to the use of mixed-integer programming. Zaric and Brandeau (2001a) use heuristics to solve the resource allocation problem developed in a previous study (i.e., Zaric \& Brandeau, 2001b). Lasry et al. (2007), in turn, compare heuristic allocation of resources to optimal allocation of resources. Finally, Kok et al. (2015) utilize a heuristic approach (i.e., simulated annealing) in addition to analytical optimization and simulation to decide on the optimal distribution of resources among different testing programs.

Only one of the selected papers applies statistical analysis (Table 5). That is, Galárraga et al. (2007) employ regression analysis to forecast the demand for ARV medicines.

\subsubsection{Type of HIV service modelled}

As can be derived from Table 6, the majority of the selected papers focuses on HIV prevention. Approximately $67 \%, 25 \%$, and $38 \%$ of the selected papers include HIV prevention, diagnosis, and treatment, respectively (these percentages add up to more than $100 \%$ as several papers focus on more than one type of HIV services).

Most of the selected papers focus solely on one HIV service (Table 6). Only three manuscripts simultaneously include two types of HIV services. Alistar et al. (2014) and Juusola and Brandeau (2016) both focus on prevention and treatment, whereas Deo et al. (2015) combine HIV diagnosis and treatment. Furthermore, two of the selected papers cover all HIV services (prevention, diagnosis, and treatment) (i.e., de Vries et al., 2020; Núñez Ares et al., 2016). 
Table 6: Classification based the type of HIV service modelled.

\begin{tabular}{ll}
\hline Type of HIV service modelled & Reference \\
\hline Prevention & Alistar et al. (2014); de Vries et al. (2020); Earnshaw et al. (2007); \\
& Juusola and Brandeau (2016); Kassa (2018); Kessler et al. (2013); \\
& Lasry et al. (2007); Lasry et al. (2011); Malvankar and Zaric (2011); \\
& Núñez Ares et al. (2016); Rauner et al. (2005); Richter et al. (1999); \\
& Vieira et al. (2003); Yaylali et al. (2016); Zaric and Brandeau (2001a); \\
& Zaric and Brandeau (2007). \\
\hline Diagnosis & De Vries et al. (2020); Deo and Sohoni (2015); Deo et al. (2015); \\
& Jónasson et al. (2017); Kok et al. (2015); Núñez Ares et al. (2016). \\
\hline Treatment & Alistar et al. (2014); Barrow et al. (2020); de Vries et al. (2020); Deo \\
& et al. (2015); Galárraga et al. (2007); Juusola and Brandeau (2016); \\
& McCoy and Johnson (2014); Núñez Ares et al. (2016); Wilson and \\
& Blower (2005). \\
\hline
\end{tabular}

\subsubsection{Challenges covered}

As became clear from the previous section, most of the selected papers focus on prevention services. As can be derived from Table 7, the challenge that is mainly studied in these papers is the allocation of limited financial resources (i.e., the allocation of limited prevention funds). Although multiple NGOs and international organizations (e.g., WHO) increased their investment in HIV prevention, funding needs still exceed the funds available (Lasry et al., 2007). Furthermore, de Vries et al. (2020) and Núñez Ares et al. (2016) focus on the limited access to HIV prevention services. However, none of the selected papers covers the frequently reported problems regarding supply uncertainty and stock-outs of prevention supplies (e.g., condoms, and VMMC kits). Also, predicting the demand for prevention supplies is not dealt with in any of the selected papers.

Our paper sample covers four challenges related to HIV diagnosis (Table 7). Deo and Sohoni (2015) and Jónasson et al. (2017) model the problems related to sample referral networks. They aim to decrease the time between the moment that a person is tested for HIV and the moment one receives the results (i.e., the turnaround time). De Vries et al. (2020) and Núñez Ares et al. (2016) cover the limited access to testing services. Kok et al. (2015) address the challenge of limited financial resources when deciding on the implementation of different HIV testing programs. Deo et al. (2015) focus on the shortage of health workers to ensure timely HIV diagnosis. An important finding from Table 7 is that none of the selected papers focusing on HIV diagnosis covers any of the other operational challenges related to the diagnosis of HIV (i.e., demand forecasting of diagnostic supplies, limited shelf life of test kits, poor laboratory infrastructure and services, and supply uncertainty and stock-outs of diagnostic supplies). 
Table 7: Classification based on challenges covered. "N.A." means that the selected paper does not consider that type of HIV service.

\section{Challenges covered}

\section{References}

Alistar et al. (2014)

Barrow et al. (2020)

De Vries et al. (2020)

Deo and Sohoni (2015)

Deo et al. (2015)

Earnshaw et al. (2007)

Galárraga et al. (2007)

Jónasson et al. (2017)

Juusola and Brandeau (2016)

Kassa (2018)

Kessler et al. (2013)

Kok et al. (2015)

Lasry et al. (2007)

Lasry et al. (2011)

Malvankar and Zaric (2011)

McCoy and Johnson (2014)

Núñez Ares et al. (2016)

Rauner et al. (2005)

Richter et al. (1999)

Vieira et al. (2003)

Wilson and Blower (2005)

Yaylali et al. (2016)

Zaric and Brandeau (2001a)

Zaric and Brandeau (2007)

Prevention

N.A.

Limited access.

N.A.

N.A.

Limited financial resources.

N.A.

N.A.

Limited financial resources.

Limited financial resources.

Limited financial resources.

N.A.

Limited financial resources.

Limited financial resources.

Limited financial resources.

N.A.

Limited access.

Limited financial resources.

Limited financial resources.

Limited financial resources.

N.A.

Limited financial resources.

Limited financial resources.

Limited financial resources.
Treatment

Limited financial resources.

Limited financial resources.

Limited access.

Limited access.

Weak sample referral networks.

N.A.

imited human resources.

Limited human resources.

N.A.

Demand forecasting.

N.A.

Weak sample referral networks.

N.A.

N.A.

N.A.

Limited financial resources.

N.A.

N.A.

N.A.

N.A.

Limited access.

N.A.

N.A.

N.A

N.A.

N.A.

N.A.

N.A.
N.A.

Limited financial resources.

N.A.

N.A.

N.A.

N.A.

N.A.

N.A.

Limited access.

N.A.

N.A.

N.A

Supply uncertainty and stock-outs.

N.A.

N.A

N.A.
Limited financial resources. 
Challenges related to HIV treatment are addressed by eight of the selected papers (Table 7). Wilson and Blower (2005) model uncertainty in supply and stock-outs of ARV medicines in health facilities. Galárraga et al. (2007) forecast the demand for ARV medicines. Alistar et al. (2014) and Juusola and Brandeau (2016) decide on the optimal allocation of limited financial resources among different prevention and treatment strategies. McCoy and Johnson (2014), in turn, allocate a treatment budget to different periods. Deo et al. (2015) address the shortage of health care workers by determining the optimal staffing level in different health facilities. Barrow et al. (2020) decide on the optimal allocation of a fixed budget among interventions aimed at maximizing clinical outcomes. Finally, de Vries et al. (2020) and Núñez Ares et al. (2016) account for the limited access to treatment services. The only challenge related to HIV treatment that is not covered in any of the selected papers is the limited shelf life of ARV drugs. Hence, Table 7 shows that OR/OM research regarding the challenges of HIV treatment is most diverse.

\subsubsection{Performance measures}

As can be derived from Table 8, approximately $96 \%, 38 \%$, and $8 \%$ of the selected papers include value, economic, and technological performance measures, respectively (these percentages add up to more than $100 \%$ as several papers include more than one performance measure).

Table 8: Classification based on performance measures. "N.A." means that no classification based on performance measures was possible.

\begin{tabular}{ll}
\hline Performance measures & Reference \\
\hline Economic & Alistar et al. (2014); Barrow et al. (2020); Deo et al. (2015); Juusola \\
& and Brandeau (2016); Kessler et al. (2013); Rauner et al. (2005); \\
& Richter et al. (1999); Yaylali et al. (2016); Zaric and Brandeau (2007). \\
\hline Technological & Deo and Sohoni (2015); Jónasson et al. (2017). \\
\hline Value & Alistar et al. (2014); Barrow et al. (2020); de Vries et al. (2020); Deo \\
& and Sohoni (2015); Deo et al. (2015); Earnshaw et al. (2007); Jónasson \\
& et al. (2017); Juusola and Brandeau (2016); Kassa (2018); Kessler et \\
& al. (2013); Kok et al. (2015); Lasry et al. (2007); Lasry et al. (2011); \\
& Malvankar and Zaric (2011); McCoy and Johnson (2014); Núñez Ares \\
& et al. (2016); Rauner et al. (2005); Richter et al. (1999); Vieira et al. \\
& (2003); Wilson and Blower (2005); Yaylali et al. (2016); Zaric and \\
& Brandeau (2001a); Zaric and Brandeau (2007). \\
\hline Galárraga et al. (2007). \\
\hline
\end{tabular}

First, almost all of the selected papers include value performance measures (Table 8). This is not very surprising since the research of HIV supply chains is situated in the field of global health. Since most of the papers focus on HIV prevention, the value dimension mainly focuses on the number of infections averted and the number of new infections (i.e., Alistar et al., 2014; Earnshaw et al., 2007; Juusola \& Brandeau, 2016; Kassa, 2018; Kessler et al., 2013; Kok et al., 2015; Lasry et al., 2011, 2007; Malvankar \& Zaric, 2011; McCoy \& Johnson, 2014; Richter et al., 1999; Yaylali et al., 2016; Zaric \& Brandeau, 2001a, 2007). This dimension also includes the quality-adjusted-life-years (QALYs) (Alistar 
et al., 2014; Deo et al., 2015; Juusola \& Brandeau, 2016; Zaric \& Brandeau, 2001a), the number of HIVpositive people receiving treatment (Barrow et al., 2020; Jónasson et al., 2017), the number of patients receiving their test results (Deo \& Sohoni, 2015; Jónasson et al., 2017), the number of persons served (de Vries et al., 2020; Núñez Ares et al., 2016; Yaylali et al., 2016), patient adherence (McCoy \& Johnson, 2014), the number of patients achieving viral suppression (Barrow et al., 2020), and the accessibility of HIV services (de Vries et al., 2020; Núñez Ares et al., 2016). Furthermore, Rauner et al. (2005) and Vieira et al. (2003) specifically focus on prevention of mother-to-child transmission including the following value performance measures: the number of pregnancies and births, the number of infected and uninfected mothers, the number of infected and uninfected newborns, the number of stillborn babies, and the number of uninfected children younger than 12 years alive after a 12-year time horizon. Finally, Lasry et al. (2007), Núñez Ares et al. (2016), and Wilson and Blower (2005) incorporate the equity criterion as a performance measure. An outcome is considered equitable if all people in need of HIV services have an equal chance of receiving it.

Second, although value performance measures are the main outcome metrics in most of the selected papers, multiple papers also report on the costs of the obtained solutions (Table 8). These cost calculations include the cost per QALY gained (Deo et al., 2015; Juusola \& Brandeau, 2016), the cost per infection averted (Kessler et al., 2013; Richter et al., 1999; Yaylali et al., 2016), implementation costs of different prevention and treatment programs (Alistar et al., 2014), implementation costs of different allocation scenarios (Zaric \& Brandeau, 2007), and the cost of different interventions to improve the HIV care continuum (i.e., maximize the number of people achieving viral suppression) (Barrow et al., 2020). Furthermore, Rauner et al. (2005) calculate a cost-effectiveness ratio (CER) which determines the extra cost per additional HIV-negative child alive for a certain prevention of mother-tochild transmission policy (e.g., the start of bottle-feeding for infants at delivery) compared to the baseline scenario (i.e., no intervention). Finally, Kessler et al. (2013) and Juusola and Brandeau (2016) utilize the incremental cost-effectiveness ratio (ICER) to evaluate their outcomes. The ICER determines the extra advantage of each possible outcome compared to its next best outcome.

Last, only two papers consider technological performance measures: Deo and Sohoni (2015) and Jónasson et al. (2017) report turnaround times in their studies.

\subsubsection{Real-life applicability}

Most of the selected papers use real-life data in their analysis (Table 9). Only one manuscript does not incorporate actual data into its study: Kassa (2018) relies on hypothetical data. Selected papers that incorporate real-life data in their study use three types of data sources. First, the data is obtained by the authors through field observations, interviews, and surveys. Second, real-life data as reported in the literature is used. Third, data is obtained from national as well as global health and humanitarian organizations (e.g., WHO, UNAIDS, National Institute for Health Mozambique, the World Bank, and the North Star Alliance). 
Table 9: Classification based on real-life applicability.

\begin{tabular}{ll}
\hline Real-life applicability & Reference \\
\hline Use of real-life data & Alistar et al. (2014); Barrow et al. (2020); de Vries et al. (2020); Deo \\
& and Sohoni (2015); Deo et al. (2015); Earnshaw et al. (2007); \\
& Galárraga et al. (2007); Juusola and Brandeau (2016); Jónasson et al. \\
& (2017) Kessler et al. (2013); Kok et al. (2015); Lasry et al. (2007); \\
& Lasry et al. (2011); Malvankar and Zaric (2011); McCoy and Johnson \\
& $(2014) ;$ Núñez Ares et al. (2016); Rauner et al. (2005); Richter et al. \\
& $(1999) ;$ Vieira et al. (2003); Wilson and Blower (2005); Yaylali et al. \\
& (2016); Zaric and Brandeau (2001a); Zaric and Brandeau (2007). \\
\hline Stakeholder involvement & De Vries et al. (2020); Deo and Sohoni (2015); Deo et al. (2015); \\
& Earnshaw et al. (2007); Galárraga et al. (2007); Jónasson et al. (2017); \\
& Kok et al. (2015); Vieira et al. (2003), Yaylali et al. (2016). \\
\hline Implementation & Deo et al. (2015); Earnshaw et al. (2007); Yaylali et al. (2016). \\
\hline
\end{tabular}

In comparison, the number of selected papers that incorporate the second degree of real-life applicability is limited. Stakeholder involvement is present in nine of the selected papers. First, Deo and Sohoni (2015), Earnshaw et al. (2007), Jónasson et al. (2017), Kok et al. (2015), and Yaylali et al. (2016) receive input from national and/or international health departments and organizations. De Vries et al. (2020) and Galárraga et al. (2007) work together with NGOs or international organizations (e.g., the North Star Alliance, the WHO, and UNAIDS). Vieira et al. (2003), in turn, cooperate with clinicians specialized in the field of mother-to-child transmissions. Because some ideas of Deo et al. (2015) have been implemented in practice, we assume that stakeholder involvement was present.

Furthermore, three of the selected papers include the third degree of real-life applicability. First, the pilot study conducted in four U.S. health departments has led to three of the four pilot scenes wanting to use the model of Yaylali et al. (2016) for future strategic decisions. Second, ideas developed by Deo et al. (2015) have been implemented in practice. Last, because Earnshaw et al. (2007) indicate that the stakeholders are willing to implement the research into practice, this paper is also classified as incorporating the third degree of real-life applicability.

\subsubsection{Countries covered}

As can be derived from Table 10, most selected papers focus on a single country. Two manuscripts cover two countries: Alistar et al. (2014) apply their model to Uganda and Russia, and Lasry et al. (2007) cover Kenya and Botswana. Also, three of the selected papers focus on a larger number of countries: De Vries et al. (2020) and Núñez Ares et al. (2016) cover fourteen and nine African countries, respectively. Furthermore, Galárraga et al. (2007) include data from 30, mainly African, LMICs. For an overview of these countries, we refer to the specific papers. 
Table 10: Classification based on countries covered.

\begin{tabular}{|c|c|c|}
\hline Countries covered & & Reference \\
\hline \multicolumn{3}{|l|}{ Single country } \\
\hline \multicolumn{3}{|l|}{ Low- and middle-income countries } \\
\hline & Botswana & Vieira et al. (2003). \\
\hline & Jamaica & Barrow et al. (2020). \\
\hline & Mozambique & Deo and Sohoni (2015); Jónasson et al. (2017). \\
\hline & South Africa & Wilson and Blower (2005). \\
\hline & Tanzania & Rauner et al. (2005). \\
\hline & Zambia & McCoy and Johnson (2014). \\
\hline \multirow[t]{2}{*}{ High-income countries } & Canada & Kok et al. (2015). \\
\hline & U.S. & $\begin{array}{l}\text { Deo et al. (2015); Earnshaw et al. (2007); Juusola } \\
\text { Brandeau (2016); Kessler et al. (2013); Lasry et al. } \\
\text { (2011); Malvankar and Zaric (2011); Richter et al. } \\
\text { (1999); Yaylali et al. (2016); Zaric and Brandeau } \\
\text { (2001a); Zaric and Brandeau (2007). }\end{array}$ \\
\hline \multicolumn{3}{|l|}{ Multiple countries } \\
\hline Low- and middle-income countries & & $\begin{array}{l}\text { Alistar et al. (2014); de Vries et al. (2020); Galárraga } \\
\text { et al. (2007); Lasry et al. (2007); Núñez Ares et al. } \\
\text { (2016). }\end{array}$ \\
\hline Not specified & & Kassa (2018). \\
\hline
\end{tabular}

It is interesting to investigate whether the models developed in the selected papers that focus on high-income countries might be applicable to LMICs as well. First, Earnshaw et al. (2007), Juusola and Brandeau (2016), Lasry et al. (2011), Malvankar and Zaric (2011), Richter et al. (1999), Yaylali et al. (2016), Zaric and Brandeau (2001a), and Zaric and Brandeau (2007) develop models for the allocation of limited financial resources. The models in these papers are applied to high-income settings but might as well be utilized in resource-limited settings (i.e., LMICs) to support allocation decisions as limited financial resources are a major challenge in LMICs (see Section 4.3.). Obviously, the application of these models in LMICs requires the correct parameter settings based on input data from LMICs.

Second, the models of Deo et al. (2015), Kessler et al. (2013), and Kok et al. (2015) are entirely based on the Greater Los Angeles, the New York, and the Vancouver healthcare systems, respectively, which are substantially different from the healthcare system in LMICs. Their models have been developed specifically for those settings. Hence, adaptations to these models are needed to apply to LMICs. Therefore, one cannot directly apply the conclusions of these papers to LMICs.

\subsection{Future research directions}

Classifying the selected papers according to the classification criteria, several tendencies and gaps are identified which might be useful for OR/OM researchers in the context of future research.

We find that current research on HIV supply chains mainly focuses on the strategic decision level, whereas OR/OM research addressing the tactical and operational decision levels is scarce. For example, tactical problems such as deciding on the transportation mode in the sample referral network and determining inventory levels of HIV supplies which are critical in organizing the HIV supply chain have 
not been covered thus far. Also, an operational decision that remains unaddressed in the existing OR/OM literature is the determination of adequate ARV buffer stocks at the national level as recommended by the WHO.

Current OR/OM literature mostly utilizes analytical optimization methods, obtaining an optimal solution. Although using simulation to verify optimization models can be very useful to include the reallife behavior of the system, OR/OM papers combining optimization models and simulation are scarce. A suggestion for future research might be to increase the use of simulation to validate the solutions of analytical models.

Regarding the different types of HIV services, OR/OM research conducted thus far mainly focuses solely on one service, to a lesser extent including multiple types of HIV services. Therefore, future research considering products for the three types of HIV services together is needed, as HIV commodities for prevention, diagnosis and treatment all make use of the same supply chain network. Also, HIV prevention has received the most attention in OR/OM research, whereas less research has been done on diagnosis and treatment. However, more challenges related to diagnosis and treatment are covered in the OR/OM literature compared to prevention. More specifically, research on HIV prevention services mainly focuses on limited financial resources whereas research on the challenges of diagnosis and treatment services is more diverse.

Modelling of the challenges of HIV supply chains is limited in the field of OR/OM. Current OR/OM research has mainly focused on the allocation of limited funds decisions. We find that a gap exists between the challenges of HIV supply chains reported in the (broad) literature and those covered in $\mathrm{OR} / \mathrm{OM}$ research. To the best of our knowledge, no OR/OM papers exist that investigate the laboratory infrastructure and services or include the limited shelf life of HIV supplies. Furthermore, demand forecasting, limited access to HIV services, weak sample referral networks, limited human resources, and supply uncertainty and stock-outs are only covered to a limited extent in OR/OM research.

Current OR/OM researchers mostly evaluate their models according to value performance measures. More specifically, the main outcome measures are related to health topics. Furthermore, many papers incorporate cost calculations in their analysis. The manuscripts incorporating technological performance measures are scarce. However, the technological dimension is important in LMICs as they typically lack sufficient resources. Hence, it might be useful to focus more on this dimension in future research or at least include it in the analysis.

Real life data is included in the analysis of most OR/OM papers. However, fewer papers incorporate the second and third degree of real-life applicability. Though, it is important to note that validating models and outcomes with stakeholders might reduce the gap between theory and practice. More stakeholder involvement, in turn, might result in more implementation of models in practice.

Last, our analysis reveals that most of the models developed in papers focusing on high-income countries could be applied to LMICs as well, if the parameter settings are based on input data from LMICs. Focusing on LMICs, OR/OM research tends to concentrate on the African continent and to a 
lesser extent on the Asian and the South-American continent. OR/OM research focusing on high-income countries concentrates solely on the U.S. and Canada. This implies that a lot of LMICs, as well as highincome countries, remain unexplored.

\section{Conclusion}

In this paper, we provide a literature review on HIV supply chains in LMICs to address three main research questions. First, how are HIV supply chains operated in LMICs and what challenges are faced by organizing such supply chains? Second, how did current OR/OM literature contribute to the organization of HIV supply chain operations? Third, in what ways can future OR/OM research contribute to improve HIV supply chains in LMICs?

The contribution of this paper to the current literature is three-fold. First, we give an extensive overview of the operations and main challenges of HIV supply chains in LMICs. To obtain a complete overview that is relevant for researchers and practitioners alike, we include a combination of (i) scientific and grey literature, and (ii) quantitative and qualitative papers in our review. To the best of our knowledge, this paper is the first literature review addressing this specific topic. Second, we classify and discuss the relevant OR/OM papers according to seven classification criteria: decision level, methodology, type of HIV service modelled, challenges covered, performance measures, real-life applicability, and countries covered. Third, throughout these classifications, we identify gaps that provide opportunities for future OR/OM research.

Although many researchers emphasize the importance of improving HIV supply chains, we find that OR/OM research focusing on HIV supply chains is limited. Only 24 papers have been identified after an extensive search through Google Scholar, PubMed, Scopus, and Web of Science.

An important conclusion that we draw from this review is that of the many issues described in the literature, only a few have been covered in the OR/OM literature. Our analysis shows that little attention has been given to supply uncertainty and stock-outs of HIV supplies despite being reported as the main challenge for HIV supply chains. Also, many other challenges that have been described in the literature remain unaddressed in OR/OM research. Furthermore, stakeholder involvement is limited in the OR/OM research that has been conducted thus far. However, including the opinion of stakeholders closely involved at the operational level of HIV supply chains might reduce the gap between theory and practice that is still very present today. Low stakeholder involvement, in turn, implies that few models have been implemented in practice. To conclude, based on our analysis, we find that OR/OM research on HIV supply chains is limited, providing many interesting opportunities for impactful future research in this field. 


\section{Bibliography}

Adeiye, A. L., Faith, A. O., Felix, S. O., Paul, A. O., Nwofe, J. O., Rukema, K. F., \& Mallak, S. K. (2019). Expanding access to viral load testing in Nigeria. International Journal of Community Medicine and Public Health, 7(1), 28. https://doi.org/10.18203/2394-6040.ijcmph20195828

Alistar, S. S., Long, E. F., Brandeau, M. L., \& Beck, E. J. (2014). HIV epidemic control-a model for optimal allocation of prevention and treatment resources. Health Care Management Science, 17(2), 162-181. https://doi.org/10.1007/s10729-013-9240-4

Auvert, B., Taljaard, D., Lagarde, E., Sobngwi-Tambekou, J., Sitta, R., \& Puren, A. (2005). Randomized, controlled intervention trial of male circumcision for reduction of HIV infection risk: the ANRS 1265 Trial. PLoS Medicine, 2(11), e298. https://doi.org/10.1371/journal.pmed.0020298

AVAC. (2019). Setting up Systems for Supply Chain Management. Retrieved from https://www.prepwatch.org/prep-planning/supply-chain-management/

Avert. (2019a). Harm reduction programming. Retrieved from https://www.avert.org/professionals/hivprogramming/prevention/harm-reduction-programming

Avert. (2019b). Prevention of mother-to-child transmission (PMTCT) of HIV. Retrieved from https://www.avert.org/professionals/hiv-programming/prevention/prevention-mother-child

Bailey, R. C., Moses, S., Parker, C. B., Agot, K., Maclean, I., Krieger, J. N., ... Ndinya-Achola, J. O. (2007). Male circumcision for HIV prevention in young men in Kisumu, Kenya: a randomised controlled trial. Lancet (London, England), 369(9562), 643-656. https://doi.org/10.1016/S01406736(07)60312-2

Barrow, G. J., Fairley, M., \& Brandeau, M. L. (2020). Optimizing interventions across the HIV care continuum: A case study using process improvement analysis. Operations Research for Health Care, 100258.

Beier, F. J. (1995). The management of the supply chain for hospital pharmacies: A focus on inventory management practices. Journal of Business Logistics, 16(2), 153. Retrieved from https://search.proquest.com/docview/212651279?accountid=17215

Berhanemeskel, E., Beedemariam, G., \& Fenta, T. G. (2016). HIV/AIDS related commodities supply chain management in public health facilities of Addis Ababa, Ethiopia: A cross-sectional survey. Journal of Pharmaceutical Policy and Practice, 9(1). https://doi.org/10.1186/s40545-016-0060-z

Bond, V., Chase, E., \& Aggleton, P. (2002). Stigma, HIV/AIDS and prevention of mother-to-child transmission in Zambia. Evaluation and Program Planning, 25(4), 347-356. https://doi.org/https://doi.org/10.1016/S0149-7189(02)00046-0

Braun, M., Kabue, M. M., McCollum, E. D., Ahmed, S., Kim, M., Aertker, L., ... Hosseinipour, M. C. (2011). Inadequate coordination of maternal and infant HIV services detrimentally affects early infant diagnosis outcomes in Lilongwe, Malawi. Journal of Acquired Immune Deficiency Syndromes (1999), 56(5), e122-e128. https://doi.org/10.1097/QAI.0b013e31820a7f2f

Case, K. K., Gomez, G. B., \& Hallett, T. B. (2019). The impact, cost and cost-effectiveness of oral pre- 
exposure prophylaxis in sub-Saharan Africa: a scoping review of modelling contributions and way forward. Journal of the International AIDS Society, 22(9), e25390-e25390. https://doi.org/10.1002/jia2.25390

Center, K. E., Gunn, J. K. L., Asaolu, I. O., Gibson, S. J., \& Ehiri, J. E. (2016). Contraceptive use and uptake of HIV-Testing among sub-saharan african women. PLoS ONE, 11(4), 1-11. https://doi.org/10.1371/journal.pone.0154213

Chesney, M. A., \& Smith, A. W. (1999). Critical Delays in HIV Testing and Care: The Potential Role of Stigma. American Behavioral Scientist, 42(7), 1162-1174. https://doi.org/10.1177/00027649921954822

Cisek, C., \& Khomani, F. (2018). Condom Distribution and Reporting Assessment. Strenghtening Linkages at National, District, Facility, and Community Levels in Malawi. Retrieved from http://www.healthpolicyplus.com/ns/pubs/82018356_CondomDistributionandReportingAssessment.pdf

Cremin, I., Alsallaq, R., Dybul, M., Piot, P., Garnett, G., \& Hallett, T. B. (2013). The new role of antiretrovirals in combination HIV prevention: a mathematical modelling analysis. AIDS, 27(3). Retrieved from https://journals.lww.com/aidsonline/Fulltext/2013/01280/The_new_role_of_antiretrovirals_in_co mbination_HIV.15.aspx

de Vries, H., van de Klundert, J., \& Wagelmans, A. P. M. (2020). The Roadside Healthcare Facility Location Problem A Managerial Network Design Challenge. Production and Operations Management, $n / a(\mathrm{n} / \mathrm{a})$. https://doi.org/10.1111/poms.13152

Deo, S., Rajaram, K., Rath, S., Karmarkar, U. S., \& Goetz, M. B. (2015). Planning for HIV Screening, Testing, and Care at the Veterans Health Administration. Operations Research, 63(2), 287-304. https://doi.org/10.1287/opre.2015.1353

Deo, S., \& Sohoni, M. (2015). Optimal Decentralization of Early Infant Diagnosis of HIV in ResourceLimited Settings. Manufacturing \& Service Operations Management, 17(2), 191-207. https://doi.org/10.1287/msom.2014.0512

Desale, A., Taye, B., Belay, G., \& Nigatu, A. (2013). Assessment of laboratory logistics management information system practice for HIV/AIDS and tuberculosis laboratory commodities in selected public health facilities in Addis Ababa, Ethiopia. Pan African Medical Journal, 15, 1-8. https://doi.org/10.11604/pamj.2013.15.46.1969

Dowling, P. (2011). Healthcare supply chains in developing countries: situational analysis. Arlington, Va.: USAID $\mid$ DELIVER PROJECT.

Earnshaw, S. R., Hicks, K., Richter, A., \& Honeycutt, A. (2007). A linear programming model for allocating HIV prevention funds with state agencies: A pilot study. Health Care Management Science, 10(3), 239-252. https://doi.org/10.1007/s10729-007-9017-8

Edgil, D., Stankard, P., Forsythe, S., Rech, D., Chrouser, K., Adamu, T., ... Njeuhmeli, E. (2011). 
Voluntary Medical Male Circumcision: Logistics, Commodities, and Waste Management Requirements for Scale-Up of Services. PLoS Medicine, 8(11), e1001128. https://doi.org/10.1371/journal.pmed.1001128

EGPAF. (2017). A Mosotho Mother's Relief: Saving Infant Lives Through Early Diagnosis and Care. Retrieved from https://www.pedaids.org/2017/05/10/a-mosotho-mothers-relief-saving-infantlives-through-early-diagnosis-and-care/

Engel, N., Wachter, K., Pai, M., Gallarda, J., Boehme, C., Celentano, I., \& Weintraub, R. (2016). Addressing the challenges of diagnostics demand and supply: insights from an online global health discussion platform. BMJ Global Health, 1(4), e000132. https://doi.org/10.1136/bmjgh-2016000132

Evans, W., Kadirov, K., Thior, I., Ganesan, R., Ulasevich, A., \& Deperthes, B. (2018). Willingness to Pay for Condoms among Men in Sub-Saharan Africa. International Journal of Environmental Research and Public Health, 16(1), 34. https://doi.org/10.3390/ijerph16010034

Faruna, T., Akintunde, E., \& Odelola, B. (2019). Leveraging private sector transportation/logistics services to improve the National Integrated Specimen Referral Network in Nigeria. Business $\begin{array}{lllll}\text { Management } \quad \text { Dynamics, } & \text { 8(7), } & \text { Retrieved }\end{array}$ https://search.proquest.com/docview/2209729921 ?accountid=17215

Finlayson, K., \& Downe, S. (2013). Why do women not use antenatal services in low- and middleincome countries? A meta-synthesis of qualitative studies. PLoS Medicine, 10(1), e1001373e1001373. https://doi.org/10.1371/journal.pmed.1001373

Fonjungo, P. N., Alemnji, G. A., Kebede, Y., Opio, A., Mwangi, C., Spira, T. J., ... Nkengasong, J. N. (2017). Combatting Global Infectious Diseases: A Network Effect of Specimen Referral Systems. Clinical Infectious Diseases, 64(6), 796-803. https://doi.org/10.1093/cid/ciw817

Ford, N., Meintjes, G., Pozniak, A., Bygrave, H., Hill, A., Peter, T., ... Siberry, G. K. (2015). The future role of CD4 cell count for monitoring antiretroviral therapy. The Lancet. Infectious Diseases, 15(2), 241-247. https://doi.org/10.1016/S1473-3099(14)70896-5

Gabriel, T., \& Tafesse, T. (2017). Supply Chain Management of Antiretroviral Drugs In Public Health Facilities In Eastern Ethiopia. Journal of Young Pharmacists, 9, 571-576. https://doi.org/10.5530/jyp.2017.9.109

Galarraga, O., O’Brien, M. E., Gutierrez, J. P., Renaud-Thery, F., Nguimfack, B. D., Beusenberg, M., ... Greener, R. (2007). Forecast of demand for antiretroviral drugs in low and middle-income countries: 2007-2008. AIDS (London, England), 21 Suppl 4, S97-103. https://doi.org/10.1097/01.aids.0000279712.32051.29

Gils, T., Bossard, C., Verdonck, K., Owiti, P., Casteels, I., Mashako, M., ... Ellman, T. (2018). Stockouts of HIV commodities in public health facilities in Kinshasa: Barriers to end HIV. PLOS ONE, 13(1). https://doi.org/10.1371/journal.pone.0191294

Gray, R. H., Kigozi, G., Serwadda, D., Makumbi, F., Watya, S., Nalugoda, F., ... Wawer, M. J. (2007). 
Male circumcision for HIV prevention in men in Rakai, Uganda: a randomised trial. Lancet (London, England), 369(9562), 657-666. https://doi.org/10.1016/S0140-6736(07)60313-4

Guliani, H., Sepehri, A., \& Serieux, J. (2014). Determinants of prenatal care use: evidence from 32 lowincome countries across Asia, Sub-Saharan Africa and Latin America. Health Policy and Planning, 29(5), 589-602. https://doi.org/10.1093/heapol/czt045

Hardon, A. P., Akurut, D., Comoro, C., Ekezie, C., Irunde, H. F., Gerrits, T., ... Laing, R. (2007). Hunger, waiting time and transport costs: time to confront challenges to ART adherence in Africa. AIDS Care, 19(5), 658-665. https://doi.org/10.1080/09540120701244943

Harries, A. D., Suthar, A. B., Takarinda, K. C., Tweya, H., Kyaw, N. T. T., Tayler-Smith, K., \& Zachariah, R. (2016). Ending the HIV/AIDS epidemic in low- and middle-income countries by 2030: is it possible? F1000Research, 5, 2328. https://doi.org/10.12688/f1000research.9247.1

Haszlinna Mustaffa, N., \& Potter, A. (2009). Healthcare supply chain management in Malaysia: a case study. Supply Chain Management: An International Journal, 14(3), 234-243.

Hwang, B., Shroufi, A., Gils, T., Steele, S. J., Grimsrud, A., Boulle, A., ... van Cutsem, G. (2019). Stock-outs of antiretroviral and tuberculosis medicines in South Africa: A national cross-sectional survey. PloS One, 14(3), e0212405-e0212405. https://doi.org/10.1371/journal.pone.0212405

Ibegbunam, I., \& McGill, D. (2012). Health commodities management system: priorities and challenges. Journal of Humanitarian Logistics and Supply Chain Management, 2(2), 161-182. https://doi.org/10.1108/20426741211260741

Itiola, A. J., Obi, C., Mohammed, A., Raji, J., Ibegbunam, I., Aguora, S., .. Odelola, B. (2019). Institutionalization of stock status report in the management of HIV/AIDS programme: experience from Nigeria. Journal of Global Health Reports, 3, e2019010. https://doi.org/10.29392/joghr.3.e2019010

Jamieson, D., \& Kellerman, S. E. (2016). The 909090 strategy to end the HIV pandemic by 2030: Can the supply chain handle it? Journal of the International AIDS Society, 19(1), 1-4. https://doi.org/10.7448/IAS.19.1.20917

Jani, I. V, \& Peter, T. F. (2013). How Point-of-Care Testing Could Drive Innovation in Global Health. New England Journal of Medicine, 368(24), 2319-2324. https://doi.org/10.1056/NEJMsb1214197 Jónasson, J. O., Deo, S., \& Gallien, J. (2017). Improving HIV Early Infant Diagnosis Supply Chains in Sub-Saharan Africa: Models and Application to Mozambique. Operations Research, 65(6), 14791493. https://doi.org/10.1287/opre.2017.1646

Justman, J. E., Koblavi-Deme, S., Tanuri, A., Goldberg, A., Gonzalez, L. F., \& Gwynn, C. R. (2009). Developing laboratory systems and infrastructure for HIV scale-up: A tool for health systems strengthening in resource-limited settings. Journal of Acquired Immune Deficiency Syndromes, 52(SUPPL. 1), 30-33. https://doi.org/10.1097/QAI.0b013e3181bbc9f5

Juusola, J. L., \& Brandeau, M. L. (2016). HIV Treatment and Prevention: A Simple Model to Determine Optimal Investment. Medical Decision Making, 36(3), 391-409. 
https://doi.org/10.1177/0272989X15598528

Kalichman, S. C., \& Simbayi, L. C. (2003). HIV testing attitudes, AIDS stigma, and voluntary HIV counselling and testing in a black township in Cape Town, South Africa. Sexually Transmitted Infections, 79(6), 442 LP - 447. https://doi.org/10.1136/sti.79.6.442

Karim, A. M., Bieze, B., \& Chimnani, J. (2008). Measuring Family Planning Logistics System Performance in Developing Countries. Arlington, Va: USAID | DELIVER PROJECT, Task Order 1.

Kassa, S. M. (2018). Three-level global resource allocation model for HIV control: A hierarchical decision system approach. Mathematical Biosciences and Engineering, 15(1), 255-273. https://doi.org/10.3934/mbe.2018011

Kebede, Y., Fonjungo, P., Tibesso, G., Shrivastava, R., Nkengasong, J., Kenyon, T., ... Ayana, G. (2016). Improved Specimen Referral System and Increased Access to Quality Laboratory Services in Ethiopia: The Role of the Public-Private Partnership. The Journal of Infectious Diseases, 213, S59-64.

Keller, M. (2016). In the Epidemic's Heart. IAVI Report: Newsletter on International AIDS Vaccine Research, pp. 12-18.

Kessler, J., Myers, J. E., Nucifora, K. A., Mensah, N., Kowalski, A., Sweeney, M., ... Braithwaite, R. S. (2013). Averting HIV infections in New York City: a modeling approach estimating the future impact of additional behavioral and biomedical HIV prevention strategies. PloS One, 8(9), e73269-e73269. https://doi.org/10.1371/journal.pone.0073269

Kok, S., Rutherford, A. R., Gustafson, R., Barrios, R., Montaner, J. S. G., \& Vasarhelyi, K. (2015). Optimizing an HIV testing program using a system dynamics model of the continuum of care. Health Care Management Science, 18(3), 334-362. https://doi.org/10.1007/s10729-014-9312-0

Kuupiel, D., Bawontuo, V., \& Mashamba-Thompson, T. (2017). Improving the Accessibility and Efficiency of Point-of-Care Diagnostics Services in Low- and Middle-Income Countries: Lean and $\begin{array}{llllll}\text { Agile Supply } \quad \text { Chain } & \text { Management. }\end{array}$ https://doi.org/10.3390/diagnostics7040058

Kuupiel, D., Tlou, B., Bawontuo, V., Drain, P. K., \& Mashamba-Thompson, T. P. (2019). Poor supply chain management and stock-outs of point-of-care diagnostic tests in Upper East Region's primary healthcare clinics, Ghana. PLOS ONE, 14(2). https://doi.org/10.1371/journal.pone.0211498

Larson, C., Burn, R., Minnick-Sakal, A., Douglas, M. O., \& Kuritsky, J. (2014). Strategies to reduce risks in ARV supply chains in the developing world. Global Health, Science and Practice, 2(4), 395-402. https://doi.org/10.9745/GHSP-D-14-00105

Larsson, E. C., Ekström, A. M., Pariyo, G., Tomson, G., Sarowar, M., Baluka, R., ... Thorson, A. E. (2015). Prevention of mother-to-child transmission of HIV in rural Uganda: Modelling effectiveness and impact of scaling-up PMTCT services. Global Health Action, 8(1), 26308. https://doi.org/10.3402/gha.v8.26308 
Lasry, A., Sansom, S. L., Hicks, K. A., \& Uzunangelov, V. (2011). A model for allocating CDC's HIV prevention resources in the United States. Health Care Management Science, 14(1), 115-124. https://doi.org/10.1007/s10729-010-9147-2

Lasry, A., Zaric, G. S., \& Carter, M. W. (2007). Multi-level resource allocation for HIV prevention: A model for developing countries. European Journal of Operational Research, 180(2), 786-799. https://doi.org/10.1016/J.EJOR.2006.02.043

Layer, E. H., Kennedy, C. E., Beckham, S. W., Mbwambo, J. K., Likindikoki, S., Davis, W. W., ... Brahmbhatt, H. (2014). Multi-Level Factors Affecting Entry into and Engagement in the HIV Continuum of Care in Iringa, Tanzania. PLoS One, 9(8), e104961-e104961. https://doi.org/10.1371/journal.pone.0104961

Malvankar, M. M., \& Zaric, G. S. (2011). Incentives for Optimal Multi-level Allocation of HIV Prevention Resources. INFOR, 49(4), 241-246. https://doi.org/10.3138/infor.49.4.241

Marlink, R. G., \& Teitelman, S. J. (2009). From the Ground up: Building Comprehensive HIV/AIDS Care Programs in Resource-limited Settings. Volume 1. Elizabeth Glaser Pediatric AIDS Foundation.

McCoy, J. H., \& Johnson, M. E. (2014). Clinic Capacity Management: Planning Treatment Programs that Incorporate Adherence. Production and Operations Management, 23(1), 1-18. https://doi.org/10.1111/poms.12036

McKone-Sweet, K., Hamilton, P., \& Willis, S. (2005). The Ailing Healthcare Supply Chain: A Prescription for Change. Journal of Supply Chain Management, 41, 4-17. https://doi.org/10.1111/j.1745-493X.2005.tb00180.x

McMahon, J. M., Myers, J. E., Kurth, A. E., Cohen, S. E., Mannheimer, S. B., Simmons, J., ... Haberer, J. E. (2014). Oral pre-exposure prophylaxis (PrEP) for prevention of HIV in serodiscordant heterosexual couples in the United States: opportunities and challenges. AIDS Patient Care and STDs, 28(9), 462-474. https://doi.org/10.1089/apc.2013.0302

Meloni, S. T., Agbaji, O., Chang, C. A., Agaba, P., Imade, G., Oguche, S., ... Kanki, P. (2019). The role of point-of-care viral load monitoring in achieving the target of $90 \%$ suppression in HIV-infected patients in Nigeria: study protocol for a randomized controlled trial. BMC Infectious Diseases, 19(1), 368. https://doi.org/10.1186/s12879-019-3983-6

Mills, E. J., Nachega, J. B., Bangsberg, D. R., Singh, S., Rachlis, B., Wu, P., ... Cooper, C. (2006). Adherence to HAART: a systematic review of developed and developing nation patient-reported $\begin{array}{lllll}\text { barriers and facilitators. } & \text { PLoS }\end{array}$ https://doi.org/10.1371/journal.pmed.0030438

Minior, T., Douglas, M., Edgil, D., Srivastava, M., Crowley, J., Firth, J., ... Lee, L. (2017). The Critical Role of Supply Chains in Preventing Human Immunodeficiency Virus Drug Resistance in Lowand Middle-Income Settings. The Journal of Infectious Diseases, 216(supp19), S812-S815. https://doi.org/10.1093/infdis/jix403 
Ministry of Health Malawi. (2014). Supply Chain Management and Logistics. Retrieved from https://www.hiv.health.gov.mw/index.php/2014-05-19-12-34-56/supply-logistics/profile

MOH Malawi. (2016). Malawi HIV Testing Services Guidelines. Retrieved from https://aidsfree.usaid.gov/sites/default/files/htc_malawi_2016.pdf

Mshana, G. H., Wamoyi, J., Busza, J., Zaba, B., Changalucha, J., Kaluvya, S., \& Urassa, M. (2006). Barriers to accessing antiretroviral therapy in Kisesa, Tanzania: a qualitative study of early rural referrals to the national program. AIDS Patient Care and STDs, 20(9), 649-657. https://doi.org/10.1089/apc.2006.20.649

Mugambi, M. L., Palamountain, K. M., Gallarda, J., \& Drain, P. K. (2017). Exploring the Case for a Global Alliance for Medical Diagnostics Initiative. Diagnostics (Basel, Switzerland), 7(1), 8. https://doi.org/10.3390/diagnostics7010008

Mukherjee, J. S., Ivers, L., Leandre, F., Farmer, P., \& Behforouz, H. (2006). Antiretroviral therapy in resource-poor settings. Decreasing barriers to access and promoting adherence. Journal of Acquired Immune Deficiency Syndromes (1999), 43 Suppl 1, S123-6. https://doi.org/10.1097/01.qai.0000248348.25630.74

Mutemwa, R., Mayhew, S., Colombini, M., Busza, J., Kivunaga, J., \& Ndwiga, C. (2013). Experiences of health care providers with integrated HIV and reproductive health services in Kenya: a qualitative study. BMC Health Services Research, 13(1), 18. https://doi.org/10.1186/1472-696313-18

Naicker, S., Plange-Rhule, J., Tutt, R. C., \& Eastwood, J. B. (2009). Shortage of healthcare workers in developing countries--Africa. Ethnicity \& Disease, 19(1), 60.

Nichols, B. E., Girdwood, S. J., Crompton, T., Stewart-Isherwood, L., Berrie, L., Chimhamhiwa, D., ... Rosen, S. (2018). Impact of a borderless sample transport network for scaling up viral load monitoring: results of a geospatial optimization model for Zambia. Journal of the International AIDS Society, 21(12). https://doi.org/10.1002/jia2.25206

Núñez Ares, J., de Vries, H., \& Huisman, D. (2016). A column generation approach for locating roadside clinics in Africa based on effectiveness and equity. European Journal of Operational Research, 254(3), 1002-1016. https://doi.org/https://doi.org/10.1016/j.ejor.2016.04.031

Obeagu, E. (2017). Evaluation of Laboratory Logistics Management Information System in HIV/AIDS Comprehensive Health Facilities in Bayelsa State, Nigeria. 3, 21-38. https://doi.org/10.22192/ijcrms.2017.03.01.004

Parekh, B., Fonjungo, P., Kalou, M., Rottinghaus, E., Puren, A., Alexander, H., ... Nkengasong, J. (2018). Diagnosis of Human Immunodeficiency Virus Infection. Clinical Microbiology Reviews, 32. https://doi.org/10.1128/CMR.00064-18

Phillips, A. N., Lee, C. A., Elford, J., Janossy, G., Timms, A., Bofill, M., \& Kernoff, P. B. (1991). Serial CD4 lymphocyte counts and development of AIDS. Lancet (London, England), 337(8738), 389392. https://doi.org/10.1016/0140-6736(91)91166-r 
Pisa, M., \& McCurdy, D. (2019, February). Improving Global Health Supply Chains through Traceability. Retrieved from https://www.cgdev.org/sites/default/files/improving-global-healthsupply-chains-through-traceability.pdf

Raja, S., \& Mohammed, N. (2004). National HIV/AIDS programs: a handbook on supply chain management for HIV/AIDS medical commodities. Retrieved from http://documents.worldbank.org/curated/en/413721468316131387/pdf/372160ENGLISH01Suppl yChain01PUBLIC1.pdf

Rauner, M. S., Brailsford, S. C., \& Flessa, S. (2005). Use of discrete-event simulation to evaluate strategies for the prevention of mother-to-child transmission of HIV in developing countries. Journal of the Operational Research Society, 56(2), 222-233. https://doi.org/10.1057/palgrave.jors.2601884

Richter, A., Brandeau, M. L., \& Owens, D. K. (1999). An analysis of optimal resource allocation for prevention of infection with human immunodeficiency virus (HIV) in injection drug users and non- $\quad$ users. Medical Decision Making, 19(2), 167-179. https://doi.org/10.1177/0272989X9901900207

Ripin, D. J., Jamieson, D., Meyers, A., Warty, U., Dain, M., \& Khamsi, C. (2014). Antiretroviral Procurement and Supply Chain Management. Antiviral Therapy, 11. https://doi.org/10.3851/IMP2903

Sandøy, I. F., Blystad, A., Shayo, E. H., Makundi, E., Michelo, C., Zulu, J., \& Byskov, J. (2012). Condom availability in high risk places and condom use: a study at district level in Kenya, Tanzania and Zambia. BMC Public Health, 12(1), 1030. https://doi.org/10.1186/1471-2458-121030

Sekhri, N. (2006). Forecasting for Global Health: New Money, New Products \& New Markets. Retrieved from https://www.cgdev.org/sites/default/files/archive/doc/ghprn/Forecasting_Background.pdf

Sharma, M., Ying, R., Tarr, G., \& Barnabas, R. (2015). Systematic review and meta-analysis of community and facility-based HIV testing to address linkage to care gaps in sub-Saharan Africa. Nature, 528(7580), S77-S85. https://doi.org/10.1038/nature16044

Shiferaw, M. B., \& Sisay Misganaw, A. (2020). Evaluation of continuous quality improvement of tuberculosis and HIV diagnostic services in Amhara Public Health Institute, Ethiopia. PLOS ONE, 15(3), e0230532. Retrieved from https://doi.org/10.1371/journal.pone.0230532

Shiferaw, M. B., \& Yismaw, G. (2019). Magnitude of delayed turnaround time of laboratory results in Amhara Public Health Institute, Bahir Dar, Ethiopia. BMC Health Services Research, 19(1), 240. https://doi.org/10.1186/s12913-019-4077-2

Shrestha, R., Philip, S., Shewade, H. D., Rawal, B., \& Deuba, K. (2017). Why don't key populations access HIV testing and counselling centres in Nepal? Findings based on national surveillance survey. BMJ Open, 7(12), e017408. https://doi.org/10.1136/bmjopen-2017-017408 
Stevens, W., Gous, N., Ford, N., \& Scott, L. E. (2014). Feasibility of HIV point-of-care tests for resource-limited settings: challenges and solutions. BMC MEDICINE, 12. https://doi.org/10.1186/s12916-014-0173-7

Tafuma, T. A., Mahachi, N., Dziwa, C., Moga, T., Baloyi, P., Muyambo, G., ... Lew, K. (2018). Barriers to HIV service utilisation by people living with HIV in two provinces of Zimbabwe: Results from 2016 baseline assessment. Southern African Journal of HIV Medicine, 19(1), 721. https://doi.org/10.4102/hivmed.v19i1.721

Tuller, D. M., Bangsberg, D. R., Senkungu, J., Ware, N. C., Emenyonu, N., \& Weiser, S. D. (2010). Transportation costs impede sustained adherence and access to HAART in a clinic population in southwestern Uganda: a qualitative study. AIDS and Behavior, 14(4), 778-784. https://doi.org/10.1007/s10461-009-9533-2

UN. (2019). Annex: Global indicator framework for the Sustainable Development Goals and targets of the 2030 Agenda for Sustainable Development. Retrieved from https://unstats.un.org/sdgs/indicators/Global Indicator Framework after 2020 review_Eng.pdf

UNAIDS. (n.d.). HIV Treatment. Retrieved from https://www.unaids.org/en/topic/treatment

UNAIDS. (2014). The Gap Report. Retrieved from https://www.unaids.org/sites/default/files/media_asset/UNAIDS_Gap_report_en.pdf

UNITAID. (2015). HIV/AIDS Diagnostics Technology Landscape. Retrieved from http://www.unitaid.org/assets/UNITAID_HIV_Nov_2015_Dx_Landscape-1.pdf

USAID. (2016). VMMC Site Ops: CHAPTER 2. Service Site Collection, Planning, Preparation, and Launch.

Retrieved

from https://publications.jsi.com/JSIInternet/Inc/Common/_download_pub.cfm?id=18878\&lid=3

USAID. (2019a). Addressing condom supply and demand in PEPFAR programs. Retrieved from https://www.usaid.gov/global-health/health-areas/hiv-and-aids/technical-areas/addressingcondom-supply-and-demand-pepfar

USAID. (2019b). Drones in Development: Innovating the Supply Chain to Reach Patients in Remote Areas. Retrieved from https://www.ghsupplychain.org/news/drones-development-innovatingsupply-chain-reach-patients-remote-areas

USAID. (2019c). FISCAL YEAR 2019: ANNUAL REPORT. Retrieved from https://www.ghsupplychain.org/sites/default/files/2020-05/GHSC-

PSM_Annual_Report_FY2019_Q4 Report_final.pdf

USAID. (2019d). Public sector management of private sector service provider helps scale up distribution of health commodities in Zambia. Retrieved from https://www.ghsupplychain.org/news/publicsector-management-private-sector-service-provider-helps-scale-distribution-health

USAID. (2019e). SUPPLY CHAIN FOR HIV/AIDS ESSENTIAL HEALTH PRODUCTS. Retrieved from https://www.usaid.gov/global-health/health-areas/hiv-and-aids/technical-areas/supplychain-hiv-and-aids-essential-health 
USAID. (2019f). Vendor Managed Inventory: Shorter Lead Time, Great Cost Savings, Larger Health Impact. Retrieved from https://www.ghsupplychain.net/sites/default/files/2019-11/148_GHSC Summit Poster_VMI FINAL.pdf

Vandaele, N. J., \& Decouttere, C. J. (2013). Sustainable R\&D portfolio assessment. Decision Support Systems, 54(4), 1521-1532. https://doi.org/https://doi.org/10.1016/j.dss.2012.05.054

Vieira, I. T., Harper, P. R., Shahani, A. K., \& De Senna, V. (2003). Mother-to-child transmission of HIV: A simulation-based approach for the evaluation of intervention strategies. Journal of the Operational Research Society, 54(7), 713-722. https://doi.org/10.1057/palgrave.jors.2601566

Wagenaar, B. H., Gimbel, S., Hoek, R., Pfeiffer, J., Michel, C., Manuel, J. L., ... Sherr, K. (2014). Stock-outs of essential health products in Mozambique - longitudinal analyses from 2011 to 2013. Tropical Medicine \& International Health, 19(7), 791-801. https://doi.org/10.1111/tmi.12314

Wahlfeld, C. C., Muicha, A., Harrison, P., Kipp, A. M., Claquin, G., Silva, W. P., .. Moon, T. D. (2019). HIV Rapid Diagnostic Test Inventories in Zambezia Province, Mozambique: A Tale of 2 Test Kits. INTERNATIONAL JOURNAL OF HEALTH POLICY AND MANAGEMENT, 8(5), 292-299. https://doi.org/10.15171/ijhpm.2019.07

Weiser, S., Wolfe, W., Bangsberg, D., Thior, I., Gilbert, P., Makhema, J., ... Marlink, R. (2003). Barriers to antiretroviral adherence for patients living with HIV infection and AIDS in Botswana. Journal of Acquired Immune Deficiency Syndromes (1999), 34(3), 281-288. https://doi.org/10.1097/00126334-200311010-00004

WHO. (n.d.). HIV/AIDS: Prevention. Retrieved from https://www.who.int/health-topics/hivaids/\#tab=tab_2

WHO. (2010). Health workforce: Achieving the health-related MDGs. It takes a workforce! Retrieved from https://www.who.int/hrh/workforce_mdgs/en/

WHO. (2012). Service delivery approaches to HIV testing and counselling (HTC): A strategic HTC $\begin{array}{llll}\text { programme } & \text { framework. } & \text { Retrieved }\end{array}$ https://apps.who.int/iris/bitstream/handle/10665/75206/9789241593877_eng.pdf?sequence=1

WHO. (2013). HIV/AIDS: 5.1 HIV testing and counselling. Retrieved from https://www.who.int/hiv/pub/guidelines/arv2013/clinical/testingintro/en/

WHO. (2016). HIV 2016-2021. from https://apps.who.int/iris/bitstream/handle/10665/246178/WHO-HIV-2016.05-eng.pdf

WHO. (2017a). End HIV/AIDS by 2030. HIV/AIDS: Framework for Action in the WHO African Region, $2016 \quad 2020 . \quad$ Retrieved $\quad 20$ from https://apps.who.int/iris/bitstream/handle/10665/259638/EndAIDSeng.pdf;jsessionid=71E7384A7766D77670E26DBD53529B03? sequence=1

WHO. (2017b). HIV/AIDS: Q\&A. Retrieved from https://www.who.int/news-room/q-a-detail/hiv-aids WHO. (2018a). Family planning/Contraception: fact sheet. Retrieved from who.int/news-room/factsheets/detail/family-planning-contraception 
WHO. (2018b). Updated recommendations on first-line and second-line antiretroviral regimens and post-exposure prophylaxis and recommendations on early infant diagnosis of HIV: interim guidance. Retrieved from https://apps.who.int/iris/bitstream/handle/10665/273632/WHO-CDSHIV-18.18-eng.pdf?ua=1

WHO. (2019a). HIV/AIDS: fact sheet. Retrieved from https://www.who.int/news-room/factsheets/detail/hiv-aids

WHO. (2019b). Prevention and control of sexually transmitted infections (STIs) in the era of oral preexposure prophylaxis (PrEP) for HIV: technical brief. Retrieved from https://apps.who.int/iris/bitstream/handle/10665/325908/WHO-CDS-HIV-19.9-eng.pdf?ua=1

Wilson, D. P., \& Blower, S. M. (2005). Designing Equitable Antiretroviral Allocation Strategies in Resource-Constrained Countries. PLOS Medicine, 2(2), e50. Retrieved from https://doi.org/10.1371/journal.pmed.0020050

Xiong, W., Hupert, N., Hollingsworth, E. B., O’Brien, M. E., Fast, J., \& Rodriguez, W. R. (2008). Can modeling of HIV treatment processes improve outcomes? Capitalizing on an operations research approach to the global pandemic. BMC Health Services Research, 8, 1-10. https://doi.org/10.1186/1472-6963-8-166

Yadav, P. (2015). Health Product Supply Chains in Developing Countries: Diagnosis of the Root Causes of Underperformance and an Agenda for Reform. Health Systems \& Reform, 1(2), 142-154. https://doi.org/10.4161/23288604.2014.968005

Yadav, P., Tata, H. L., \& Babaley, M. (2011). The world medicines situation 2011. Retrieved from https://asrames.org/wp-content/uploads/2012/04/THE-WORLD-MEDICINES-SITUATION2011-STORAGE-AND-SUPPLY-CHAIN-MANAGEMENT.pdf

Yaylali, E., Farnham, P. G., Schneider, K. L., Landers, S. J., Kouzouian, O., Lasry, A., ... Sansom, S. L. (2016). From theory to practice: Implementation of a resource allocation model in health departments. Journal of Public Health Management and Practice, 22(6), 567-575. https://doi.org/10.1097/PHH.0000000000000332

Zachariah, R., Ford, N., Philips, M., S.Lynch, Massaquoi, M., Janssens, V., \& Harries, A. D. (2009). Task shifting in HIV/AIDS: opportunities, challenges and proposed actions for sub-Saharan Africa. Transactions of the Royal Society of Tropical Medicine and Hygiene, 103(6), 549-558. https://doi.org/10.1016/j.trstmh.2008.09.019

Zaric, G. S., \& Brandeau, M. L. (2001a). Optimal investment in a portfolio of HIV prevention programs. Medical Decision Making, 21(5), 391-408. https://doi.org/10.1177/0272989X0102100506

Zaric, G. S., \& Brandeau, M. L. (2001b). Resource allocation for epidemic control over short time horizons. Mathematical Biosciences, 171(1), 33-58. https://doi.org/10.1016/s00255564(01)00050-5

Zaric, G. S., \& Brandeau, M. L. (2007). A little planning goes a long way: multilevel allocation of HIV prevention resources. Medical Decision Making: An International Journal of the Society for 
Medical Decision Making, 27(1), 71-81. https://doi.org/10.1177/0272989X06297395 